\title{
Rectangular blocks vs polygonal walls in archaeoseismology
}

\author{
Klaus-G. Hinzen ${ }^{1,}$, Arnaud Montabert ${ }^{2}$ \\ ${ }^{1}$ Earthquakegeology and Archaeoseismology Group, Institute of Geology and Mineralogy, Cologne University, Bergisch \\ Gladbach, Germany \\ ${ }^{2}$ Department of Geosciences, École Normale Supérieure, PSL Research University Paris, France
}

\author{
Article history \\ Received August 2, 2016; accepted April 12, 2017. \\ Subject classification: \\ Archaeoseismology, Collapsed wall, Polygonal wall, Back calculation of ground motion.
}

\begin{abstract}
Collapsed or deformed walls in ancient structures constitute important evidence in archaeoseismology, where damage is interpreted in terms of earthquake ground motion. A large variety of wall types have been developed during the millennia in different cultural backgrounds. Often walls with polygonal-shaped building blocks are regarded as more earthquake-resistant than a wall consisting of rectangular elements and, as is sometimes speculated, that the irregular wall types were intentionally developed for that purpose. We use simply structured discrete element models of four walls with different block geometries, perfect rectangular, an Inca-type structure and two polygonal designs, to test their dynamic behavior. In addition to an analytic calculation of ground motion, we use measured strong motion signals as boundary conditions for the 3D wall models with varying height to width ratios. At peak ground accelerations between 1.0 and $9.0 \mathrm{~m} / \mathrm{s}^{2}$ and major frequencies of 0.5 to $3 \mathrm{~Hz}$, numeric experiments with the horizontally applied analytic ground motions result in clear differences in the resistance of the four wall types with the rectangular block wall being most vulnerable. For more complex measured 3D motions the Inca-type wall proves more stable than the rectangular block wall; however, height to width ratio still has equally strong influence on the stability. Internal deformation of non-collapsed walls shows some correlation with the parameters of the driving motion. For simple impulsive ground motions, a peak ground displacement threshold exists between toppling and remaining upright for all four models but peak acceleration cannot be reliably back calculated.
\end{abstract}

\section{Introduction}

Cracked or toppled walls are often interpreted as strong evidence for a seismogenic cause of damage in archaeoseismology [e.g. Korjenkov and Mazor 1999, Galadini et al. 2006, Marco 2008]. However, walls develop cracks and topple in many instances without any earthquakes [Ambraseys 1973, 2006].

In the early days of seismology, no instruments existed with which ground motions during earthquakes could be registered. During that period macroseismic observations were the only data available to characterize both size and intensity of earthquakes. Therefore, close attention was paid to the nature of damaged structures. Often the work of Robert Mallet [1862] carried out after the Great Neapolitan earthquake, is regarded as the 'true' starting point of modern seismology. The use of his engineering skills and by utilizing the possibilities afforded by the burgeoning field of photography assured him an important position in the history of seismology. With emerging instrumental seismology and an accelerating sophistication of devices for recording ground motion at the beginning of the $20^{\text {th }}$ century, the techniques and observation intensity initiated by Mallet [1862] were no longer widely applied. However, as contemporary archaeoseismologists are in similar situations to early seismologists like Mallet, i.e. lacking instrumental records, some of the techniques have been recently revived [e.g. Karcz and Kafri 1978, Korjenkow and Mazor 1999, Mazor and Korjenkow 2001, Galadini and Gali 2001] or extended, e.g. to rotated objects [Cucci and Tertulliani 2011, Hinzen et al. 2013]. Related is the field of precariously balanced rocks [Brune and Whitney 1992, Brune 1996, Purvance et al. 2008] which, like archaeological remains, can be used as seismoscopes to estimate ground motion levels that have not been exceeded since the objects attained their current form.

However, often basic common sense is applied to the interpretation of potential earthquake damage in archaeological findings or in persisting monuments [Galadini et al. 2006, Marco 2008]. This type of thinking also applies to the interpretation of the development of earthquake resistant building techniques in 
antiquity. In many popular sources it is taken for granted that in earthquake prone areas, including the Mediterranean, the Near East, western South America, and Japan, the development of polygonal walls was the result of an intentional earthquake resistant design process. Unfortunately, in the scientific literature only a few studies exist which have attempted to quantify the extent or even address the existence of this hypothesis.

As described by Scranton [1962] and Nevis (https:/ / www.coastal.edu/ashes2art/delphi2/ misc-essays/masonry.html, last accessed May 2016) styles of Greek masonry for example follow a defined chronological order starting with dry-rubble construction prior to the $6^{\text {th }}$ century BCE up to Ashlar masonry ending in the second century BCE. Styles include Lesbian, Polygonal, Trapezoidal, and Ashlar and each style of masonry presents its own challenges and benefits. In general, the technology used to build the walls of the greatest Greek monuments becomes more complex and the walls themselves become stronger and more refined with time.

The dry-rubble building method is just a stacking of rocks to form a rudimentary and somewhat unstable wall [Scranton 1962]. The earliest technique using cut stone with surface treatment is called the Lesbian style which was popular in the $6^{\text {th }}$ century BCE and no evidence of Lesbian masonry has been found that postdates the Greco-Persian Wars (499-449 B.C.E.). The best examples of it are found on the Isle of Lesbos, explaining the name. The style consists of entirely curved joints with mostly a quarry faced surface, a tooled surface, or a pointed surface [Scranton 1962]. This style of work appears somewhat random without any defined courses and does not use mortar or clamps. The stones are carved to fit the ones around them.

Polygonal masonry is of a similar style to Lesbian masonry; however, the stone is cut into blocks with straight sides, typically more than four and non-parallel at defined angles [Scranton 1962]. The joints for this type of masonry are extremely tight, almost invisible, but are occasionally beveled to show the pattern of the stones. It generally dates from the $5^{\text {th }}$ to the $3^{\text {rd }}$ century BCE.

Another style that does not employ mortar or clamping is trapezoidal masonry [Lawrence 1957]. Walls are constructed from rectangular blocks with slanted vertical joints where two opposite sides of the block are parallel and the other two sides are not [Scranton 1962]. This style probably evolved from irregular trapezoidal work which is a mixture of polygonal and true trapezoidal masonry. Examples date from 425 to
375 BCE. Trapezoidal masonry uses isodomic (courses of equal height) and non-isodomic (courses of different heights) [Scranton 1962, Wright 2009]. In the Inca culture of South America, blocks with more than four right angle corners were introduced, classified by Torres [2014] as masonry of tight blocks of irregular size. He further describes the good earthquake-resistant performance of ancient monumental structures in the Peruvian Andes.

Ashlar masonry dates back to the Mycenaean Period, and was developed further in Hellenistic and Roman times. As it was costly [Lawrence 1957], it was generally restricted to temples and monumental buildings. Most styles of Ashlar masonry are isodomic with a few examples of pseudo-isodomic using only two sizes of coursing [Scranton 1962, Wright 2009]. Often the rectangular blocks are held together using clamps (horizontal) and dowels (vertical).

Liberatore et al. [2003] classified contemporary archaeological heritage according to earthquake vulnerability. They concentrated on cases in Italy which includes besides the vast amount of Roman structures also Etruscan and Greek constructions. Considering that vulnerability is strongly dependent on shape, material and boundaries, they also state that the decay of the building materials play a decisive role in heritage preservation. Other factors include hydrogeologic instability, meteorological and climatic conditions, prior damage by earthquakes, and anthropogenic actions.

Mistler et al. [2006] used the Aachen Cathedral, originating from the $9^{\text {th }}$ century CE, as a case study to model historic masonry under seismic excitation. They point out that the study of existing masonry structures is complicated by the variations in materials and building techniques. Often, the necessary data to build a model are simply unavailable. A major challenge for existing modeling techniques is making a reasonable approximation to brick or stone mortar joint behavior and to cover all three possible failure modes: shear failure, friction failure and bending failure. For walls without mortar or clamping systems, Mistler et al. [2006] explicitly suggest using discrete element models (DEMs) to quantify this dynamic behavior.

Yerli et al. [2011] rated the vulnerability of Lycian polygonal structures in Pinara (Southwest Turkey) as class 'A' or 'B' (high vulnerability) following the European Macroseismic Scale (EMS) [Grünthal 1993]. This is a higher vulnerability than what they assumed for massive stone masonry of ashlar blocks which they rated class 'C' or ' $D$ '.

The dynamic behavior of a simple gravity wall 
of rectangular blocks was studied by Hinzen [2009a, b] using a wall of the Triolo temple at Selinunte, Sicily as a template for a discrete element model. Even though only sinusoidal ground motions were used, a correlation between the impact pattern of the toppled wall and the maximum ground acceleration was shown.

In terms of numeric models, masonry walls can be a real challenge [Mistler et al. 2006] and lack of (as mentioned above) precise material data and material laws can introduce large uncertainties in the results of such calculations. However, sophisticated answers to basic questions can be expected for simple well-known structures. Our primary approach in this contribution is examining the influence of the geometry of (ideal-shaped) building blocks. The main questions we aim to answer are (1) whether polygonal walls are in general more earthquake resistant than walls of rectangular blocks and (2) what conclusions can be drawn from the pattern of toppled walls or internal deformation in terms of driving forces or ground motions.

\section{Method}

The study of ancient structures under earthquake loading has become an established tool in archaeoseismology and when the cause of structural deformation or a partial or total collapse is studied, DEMs have successfully been applied [e.g. Sinopoli 1995, Hinzen 2005, 2009c, 2010, Psycharis 2007, Caputo et al. 2010, Ambraseys and Psycharis 2012, Kamei and Katzor 2007]. However, this method best works with simple structures [Mistler et al. 2006]. For more complex situations, the number of unknowns in the modeling process becomes large, resulting in a high uncertainty of the achieved results. Generic models can help to overcome this limitation and help to quantify basic dynamic behavior of building components and damage processes [e.g. Hinzen 2009c, 2010].

We use in the following a discrete element model of a wall with perfect rectangular blocks in comparison to three walls of the same overall dimension and mass but with different polygonal designs. At first the reaction of such walls to analytic ground motions of altered amplitude and frequency content oriented at changing directions with respect to the wall trend is tested. Thereby, the influence of the wall height to wall width ratio (h/w-ratio) is taken into account; however, no vertical movements are applied. In a second series of tests, selected measured strong ground motions of earthquakes are used as boundary conditions. In this case, the full $3 \mathrm{D}$ ground motion is applied and again the $\mathrm{h} / \mathrm{w}$-ratio is varied.
The discrete element models have been created with the Unity3D software development tool which utilizes the physics engine PhysX (see data and resources), a combination that has been previously applied in archaeological studies (ONeill, http://www. sas.upenn.edu/ancient/againstgravity_abstracts. html, last accessed May 2016). For the current project, scripts in C-Sharp language were written to facilitate automation of scanning projects with easy handling of parameter changes. In this way, several thousand of dynamic test calculations were conducted and individual blocks monitored within reasonable amounts of modeling times. Energy dissipation during impacts between blocks was controlled by a coefficient of restitution of 0.86 . To detect potential impacts of blocks a contact offset of 0.02 was chosen; this means when blocks come closer than $0.04 \mathrm{~m}$ they are monitored for a possible impact. The collision shape was defined by a mesh following the graphic shape of each block. For solving the equations of motion a semi-implicit Euler algorithm was used.

\section{Block Wall Models and Ground Motions}

\subsection{Four Wall Models}

Test wall dimensions were chosen following an earlier test [Hinzen 2009b] in which a wall of the Triolo Temple in Selinunte, Sicily, functioned as the archetype. The test walls are $3.25 \mathrm{~m}$ high and $10.0 \mathrm{~m}$ in length. The wall widths were chosen to be $0.3,0.45$ and $0.6 \mathrm{~m}$, which gives $\mathrm{h} / \mathrm{w}$-ratios of $10.8,7.2$, and 5.4, respectively; these three cases will be designated $\mathrm{W} 1, \mathrm{~W} 2$, and $\mathrm{W} 3$ in the following. Density of the material was set to $2.4 \mathrm{Mg} / \mathrm{m}^{3}$.

Figure 1 shows the internal structure of the models, a rectangular block wall (RBW), an Inca-type wall (ITW), and two differently-structured polygonal walls (PW1, and PW2). The archetypes of these include (1) a Roman rectangular block wall; the example shown in the photo in Figure 1 is the back of a mausoleum in Patara, Turkey; (2) the famous Inca wall in Cuzco, Peru; (3) a Lycien polygonal wall in Pınara, Turkey; and (4) a Roman polygonal wall in Alba Fucens, Italy. All joints were assumed to be perfectly flat, and the walls are modeled as pure gravitational, i.e. without binding mortar or clamping devices. To avoid unrealistic sliding of the wall on the baseplate, threshold strength of the joints of the bottom row of blocks in all walls of $0.4 \mathrm{MN} / \mathrm{m}^{2}$ was introduced. Coulomb friction was assumed for all joints with a static and dynamic coefficient of friction of 0.6 and 0.5 , respectively.

This strong idealization of any ancient construction 

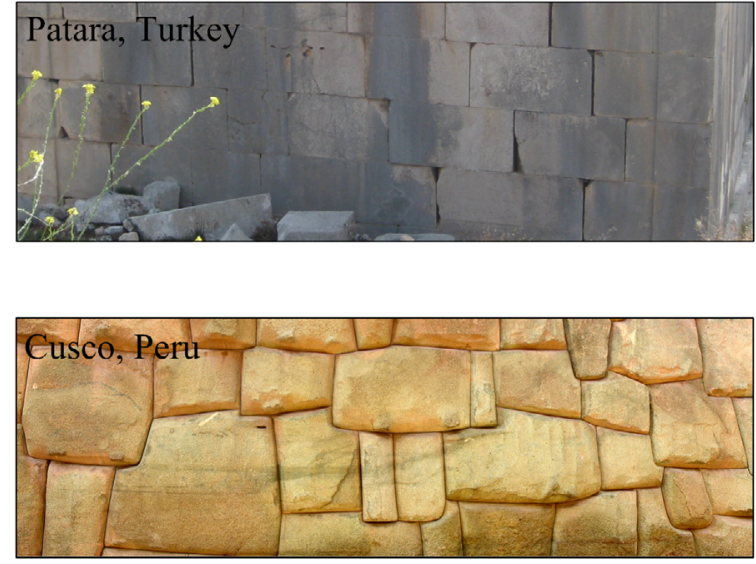

\section{RBW (52)}
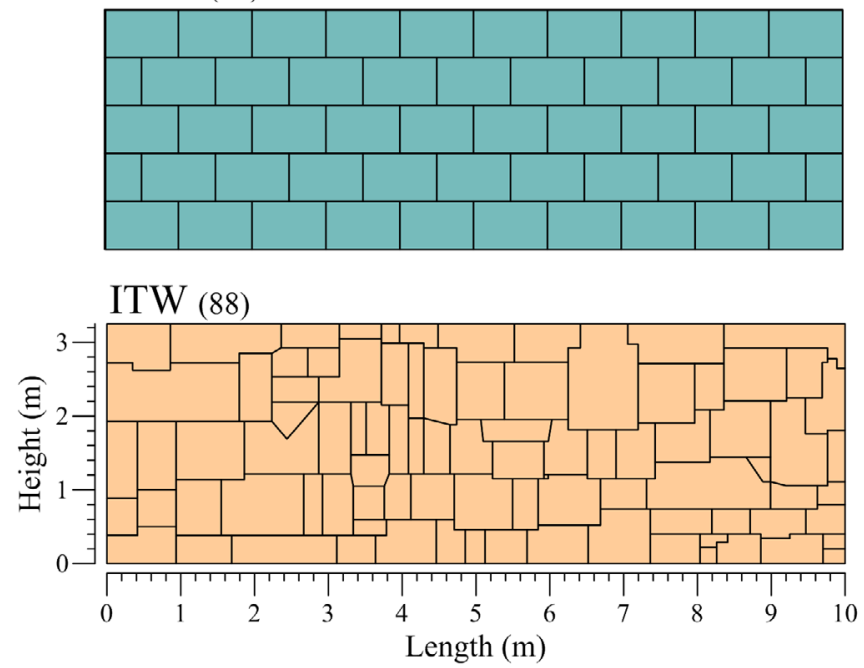
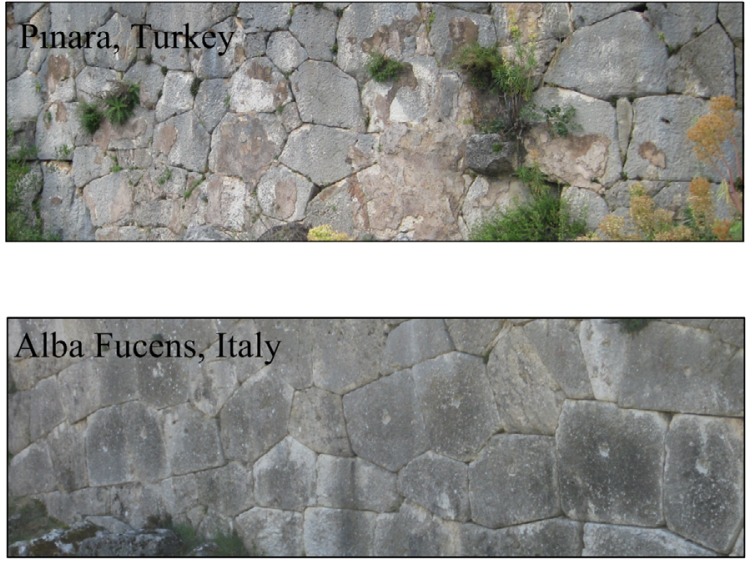

PW1 (89)

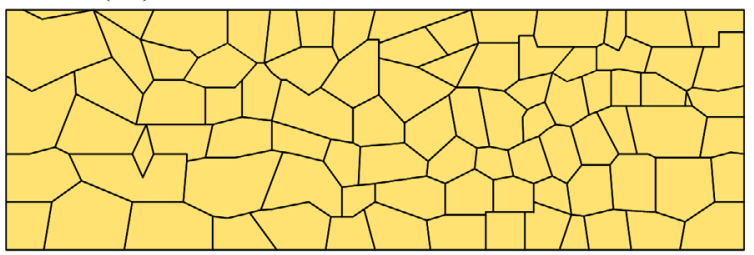

PW2 (99)

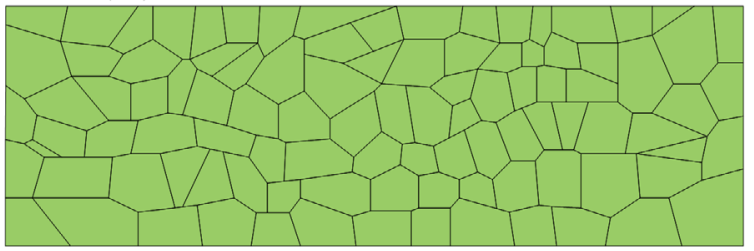

Figure 1. The photos in the two top rows show examples of ancient walls which were used as a rough guide during the model construction. Below are shown four types of wall geometries (RBW - Rectangular Block Wall, ITW - Inca Type Wall, PW1 - Polygonal Wall 1, PW2 Polygonal Wall 2) which were used for dynamic testing. The numbers in brackets give the amount of physical blocks of each wall. (Photo credit: ITW: Martin St-Amant - Wikipedia - CC-BY-SA-3.0, all other K.-G. Hinzen).

suffices for the purpose of this study; that is, quantifying the influence of the block geometry. Reconstruction of actual walls requires a more intensive modeling effort and exceeds the focus of the present study.

Further specifications of the four test walls are displayed in Figure 2. The distributions of block sizes as shown in the figure are characteristic of the entire wall face. Even though the selections are by necessity arbitrary, we sought to reproduce block size and distribution of real existing walls. The RBW has only two sizes, that of the major blocks and the half blocks at the edges. The other walls show an approximately Gaussian distribution of the block sizes where ITW and PW1 contain a bigger amount of larger blocks than PW2.

For many ancient polygonal walls, it is not well known how they are internally structured. Even though it is unlikely that neighboring blocks would be perfectly matched throughout the internal structure, for ease of calculation in our models, internal block faces are in orthogonal planes with respect to the trend of the wall(s).

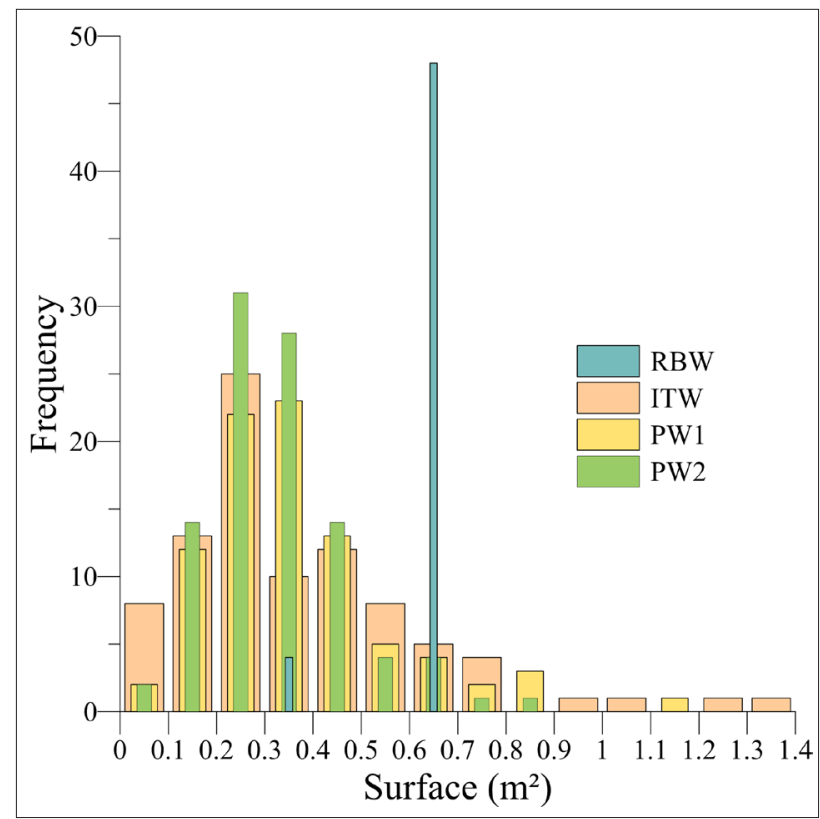

Figure 2. Frequency distribution of the block size of the four walls shown in Figure 1. Blocks are scaled by the surface area of their frontal face. 


\subsection{Cycloidal Pulse}

Analytic ground motion signals for testing the dynamic behavior of archaeoseismological models should meet the boundary condition of an initial zero displacement, velocity, and acceleration. Morlet wavelets [Hinzen et al. 2010] and cycloidal pulses [Zhang and Makris 2001] meet these criteria. We decided on the latter because they are simple, involve only one complete acceleration cycle, and the displacement resembles that of a nearfield shear dislocation source. Figure 3 shows the form of the cycloidal pulse which was applied with varying maximum displacement and duration and the acceleration response spectra of all 54 test signals.

\subsection{Earthquakes}

A set of 24 earthquake strong motion records was selected from the Center for Engineering Strong Motion Data (CESMD) and the European Strong-Motion Database (ESD) (see data and resources). In order to cover a sufficiently broad range of ground motion characteristics, no limitations were set for the source mechanism and the subsurface condition at the recording sites, with the exception that only free field station data were used. We selected records with PGAs of the horizontal ground motion component ranging from $1.0 \mathrm{~m} / \mathrm{s}^{2}$ to $8.0 \mathrm{~m} / \mathrm{s}^{2}$ in steps of 1.0 $\mathrm{m} / \mathrm{s}^{2}$. If available from the databases, the corrected displacement records were used; otherwise, displacement was calculated from the acceleration records af- ter a standard baseline correction. Figure 4 shows the elastic acceleration response spectra of all 24 earthquake records for $5 \%$ of the critical damping. Table 1 lists the most important parameters. (A plot of the displacement seismograms is shown in Figure S6 available in the electronic supplement to this article.)

Additionally, Figure 4 shows the displacement of the central block of the top row of each wall type orthogonal to the wall trend for walls that did not collapse. From such records the average period of this free oscillation was determined and plotted together with the response spectra.

\section{Calculations}

Prior to the dynamic testing of the walls we did a series of test calculations to verify the correctness of numerical solutions by comparing them to analytic calculations. Figure 5 shows two examples. In order to control the timing during all tests, we used a free falling block and recorded its time-distance behavior. In Figure 5 calculated positions are shown in comparison with the analytic values of a block falling under $9.81 \mathrm{~m} / \mathrm{s}^{2}$ acceleration for a time duration of $20 \mathrm{~s}$. The second example is that of a rocking rectangular block with a h/w-ratio of 5.0 [Hinzen et al. 2010]. Housner [1963] gives the equations to calculate the amplitudes for such a rocking motion. Test calculations showed, that a time step of $0.001 \mathrm{~s}$ is a suitable compromise between precision and calculation time for the types of models in this study.
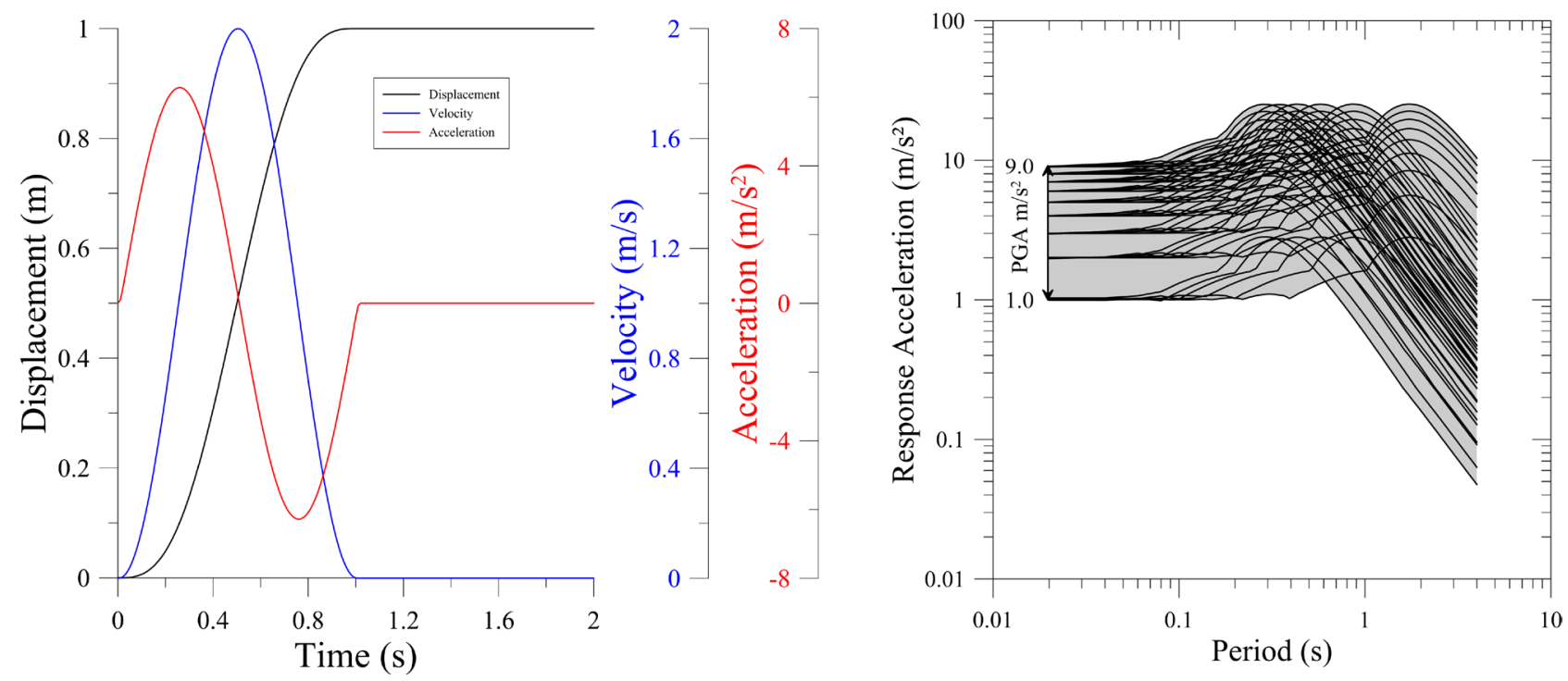

Figure 3. left: Ground displacement, velocity, and acceleration of a cycloidal pulse. In this example, the maximum displacement of $1.0 \mathrm{~m}$ is reached within $1.0 \mathrm{~s}$. Right: 54 elastic acceleration response spectra with $5 \%$ critical damping for the cycloidal impulses with PGAs from 1.0 to $9.0 \mathrm{~m} / \mathrm{s}^{2}$ and frequencies from 0.5 to $3 \mathrm{~Hz}$. Impulses with this response were used for 7776 simulations with four different walls, three height/width-ratios, and 12 ground motion directions. 

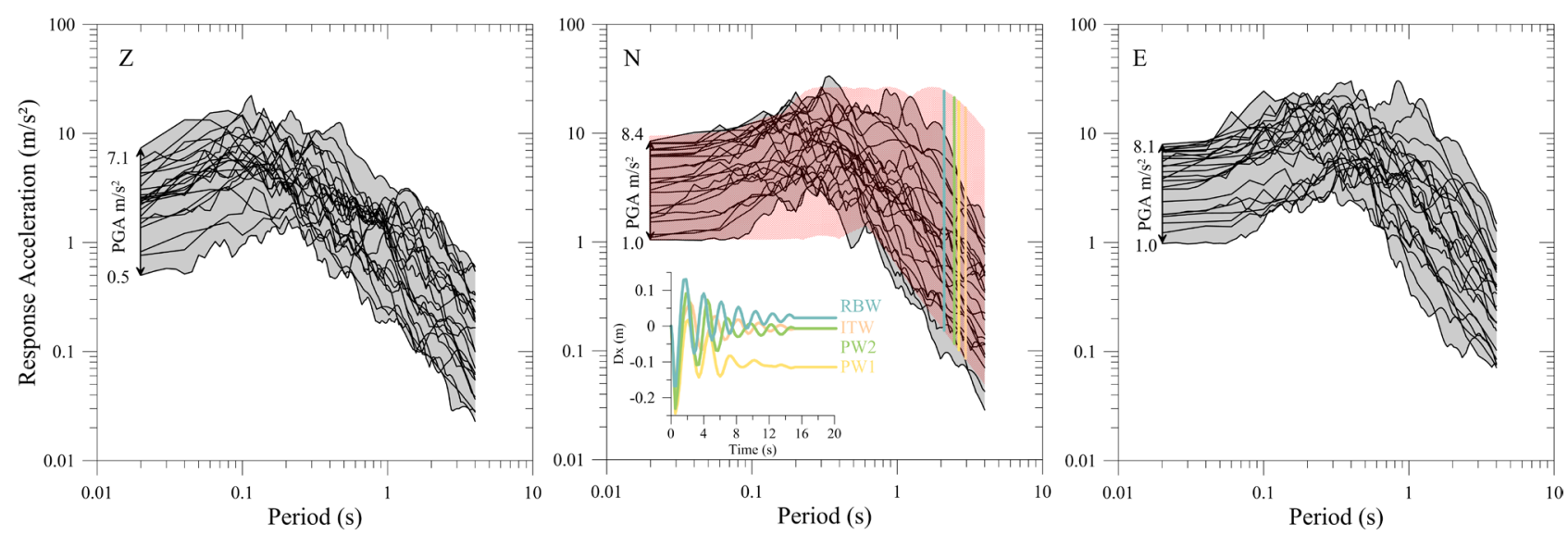

Figure 4. Acceleration response spectra for the vertical (Z), North-South $(\mathrm{N})$, and East-West (E), component of ground motion of 24 records listed in Table 1. The gray area shows the overall range of response accelerations covered by the data; black lines give the individual spectra. The PGA range covered by each component is indicated at the low period end of the spectra. The red hatched area in the plots of the $\mathrm{N}$ component gives the range of response accelerations covered by the Cycloidal pulse (Figure 3). The colored vertical lines indicate the average dominating period for the four wall types. The insert in the middle graph shows the motion of the middle block of the top row for each of the wall types.

For each of the four wall models, test series with cycloidal pulses with major frequencies of $0.5 \mathrm{~Hz}$ to $3.0 \mathrm{~Hz}$ and peak ground accelerations (PGA) from 1.0 to $9.0 \mathrm{~m} / \mathrm{s}^{2}$ were used. These motions were applied to the four walls with three $\mathrm{h} / \mathrm{w}$-ratios each and in directions from $0^{\circ}$ to $330^{\circ}$ in steps of $30^{\circ}$. Numerous scripts were written to automate the calculation procedures in UNITY. The software made it possible to: (1) make a visual inspection of the toppling process for each model during the simulation (three animated examples are available in the electronic supplements), (2) produce an output of screen shots of the final resting position of all blocks, (3) make a determination

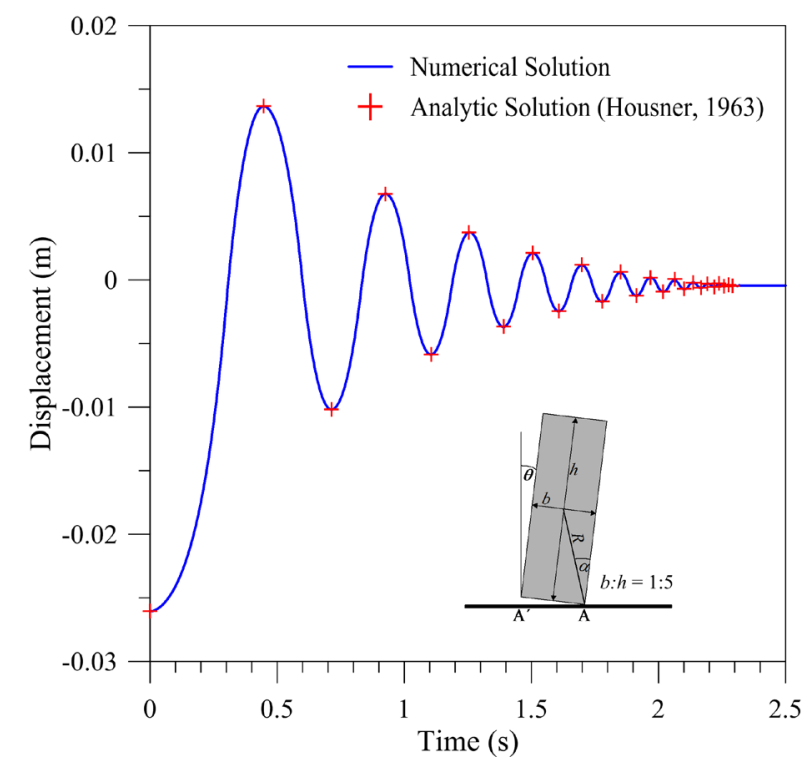

of the modulus of the displacement vector (MDV) of the center of gravity of each block, and (4) record the motion history of selected blocks. In the following section we show examples of selected simulations and summarize the results of all 7776 tests from this series. For the tests with earthquake records, all three components of ground motion were applied.

\section{Results}

Resultant to the tests, the final positions of the walls with the largest $\mathrm{h} / \mathrm{w}$-ratio (W1) and the ground motion directing at $45^{\circ}$ with respect to the wall trend is shown in Figure 6. The same color scheme for the

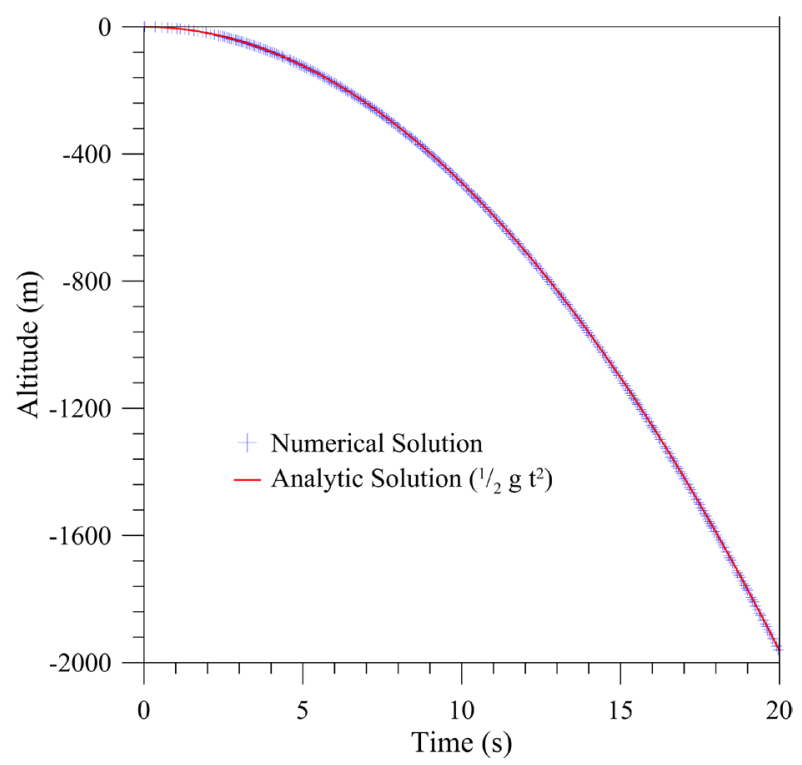

Figure 5. Verification tests of the physics engine for a rocking block (left) and a free falling object (right). On the left the blue line shows the horizontal displacement of the center of gravity of a rectangular block rocking over the corners A and A' with a height to width ratio of 5 as indicated in the insert. The red crosses give the amplitudes predicted by analytic solution of Housner (1963). The blue crosses on the right show the time-distance relation of a free falling block as numerically simulated for a period of $20 \mathrm{~s}$. The red curve gives the analytic solution for $g=9.81 \mathrm{~m} / \mathrm{s}^{2}$. 


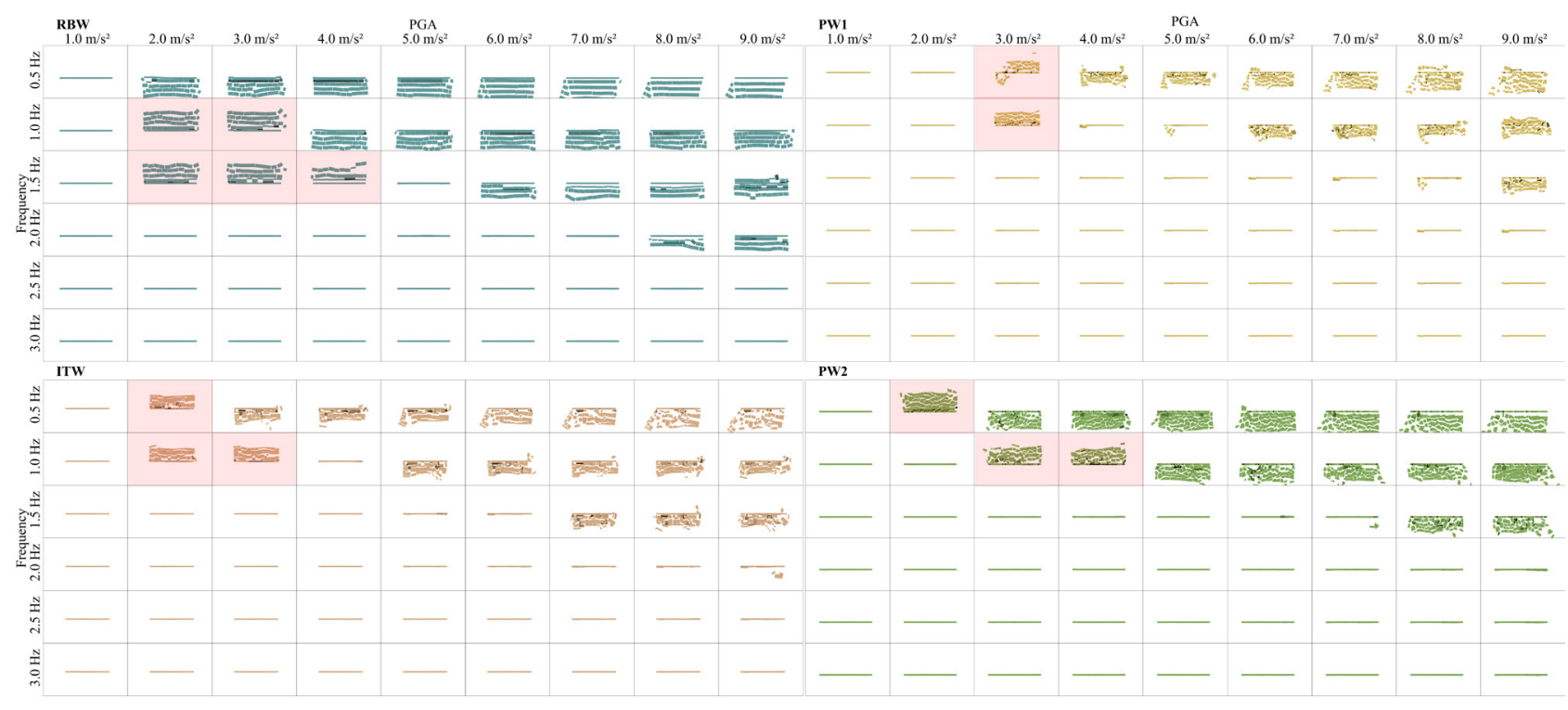

Figure 6. Example of screenshots of the final resting position of blocks of four wall geometries, RBW, ITW, PW1, and PW2 for tests with cycloidal pulses. The examples show the case of the largest h/w ratio of 10.7 (W1) of the walls and an oblique horizontal ground motion towards $45^{\circ}$. PGA and frequency of the pulses is given above and left of the graphs, respectively. Light red background indicates toppling with the impulse direction, otherwise towards the opposite site.

walls is used as in Figure 1 and is maintained throughout this publication. In this top view walls that 'survived' the test appear as a straight line. Visual inspection of the impact pattern of the toppled walls indicates a wider stray field in case of the largest PGAs, particularly for the tests with the lower frequency signals. The diagonal in the PGA-frequency matrix separating the survived from the collapsed walls shows the increase of the probability of structural failure with decreasing frequency and increasing PGA. At the transition from survival to toppling the increased sensitivity of the wall edges becomes visible, particularly for the ITW and the PW2. As can be seen in the figure, ITW is more stable than RBW in this case. The impulse in this example is always directed towards $45^{\circ}$ (NW-direction). In general if the wall topples due to the inertial effect it falls towards $180^{\circ}$ opposite to the direction of the ground movement. However, in cases of low PGA and (relative) low frequency, which are marked in Figure 8, it topples in the direction of the ground motion and this occurs during the stop phase of the Cycloidal pulse, an indication of two different failure mechanisms [Zhang and Makris 2001]. (The corresponding plots for $\mathrm{h} / \mathrm{w}$-ratios $\mathrm{W} 2$ and $\mathrm{W} 3$ are shown in Figures S1 and S2 and those for tests with the earthquake records in S3 to S5, available in the electronic supplement to this article.)

Watching the wall behavior during the deformation process is most informative; however, Figure 6 illustrates the ultimate fate of the walls. In order to quantify results, we used a measure introduced by Hinzen [2010] in the study of toppling columns: the modulus of the displacement vector (MDV) which connects the center of gravity of a block at the beginning of the numerical test with its current or final position. This is a measure which can be also estimated in archaeoseismological field cases. Figure 7 schematically shows this simple concept. With the MDVs calculated for all blocks at the end of one test, their distribution is highlighted by box-plots which indicate the median and the first and third quartile.

The MDVs, taken over all experiments, span a large range of values, therefore, in Figure 8 a logarithmic radius axis is used for their display in the form of angular boxplots. For cases where the wall survived the test intact, the MDVs form a narrow distribution of values at a relatively low level indicating small internal block displacements. If the entire wall topples, the distribution is again narrow, but at a much higher level of values above $1.0 \mathrm{~m}$. A partially collapsed wall is always indicated by a wide spread of MDVs. If the majority of blocks fell, the median of the MDV is close the third quartile, and if the majority was stable, the median is closer to the first quartile. Figure 8 shows the MDVs for all experiments with a Cycloidal motion for the walls with the highest $\mathrm{h} / \mathrm{w}$-ratio (W1). For walls that do not topple, the internal block shift in general decreases slightly with increasing frequency and it increases with increasing PGA shown by the changing radiuses of the colored rings, which ranges from the 
Table 1.

\begin{tabular}{|c|c|c|c|c|c|c|c|c|c|c|c|}
\hline & $\begin{array}{c}\text { Earthquake } \\
\#\end{array}$ & $\begin{array}{l}\text { Earthquake } \\
\text { Location }\end{array}$ & $\begin{array}{c}\text { Date } \\
\text { yyyy-mm-dd }\end{array}$ & $\begin{array}{l}\text { Time } \\
\text { UTC }\end{array}$ & $\mathbf{M}$ & Latitude & Longitude & Station & $\begin{array}{l}\text { Epicentral } \\
\text { Distance } \\
\quad(\mathbf{k m})\end{array}$ & Comp. & $\begin{array}{l}\text { PGA } \\
\left(\mathrm{m} / \mathrm{s}^{2}\right)\end{array}$ \\
\hline \multirow{9}{*}{ PGA1 } & \multirow{3}{*}{1} & \multirow{3}{*}{$\begin{array}{c}\text { New } \\
\text { Zealand }\end{array}$} & \multirow{3}{*}{ 2016-02-14 } & \multirow{3}{*}{$00: 13: 43$} & \multirow{3}{*}{5.7} & \multirow{3}{*}{$43.50^{\circ} \mathrm{S}$} & \multirow{3}{*}{$172.83^{\circ} \mathrm{E}$} & \multirow{3}{*}{ CBGS } & \multirow{3}{*}{11.0} & $Z$ & 0.54 \\
\hline & & & & & & & & & & $\mathrm{N}$ & 1.04 \\
\hline & & & & & & & & & & E & 0.96 \\
\hline & \multirow{3}{*}{2} & \multirow{3}{*}{$\begin{array}{c}\text { Friuli } \\
\text { (afterskock) }\end{array}$} & \multirow{3}{*}{ 1976-09-15 } & \multirow{3}{*}{ 03:15:19 } & \multirow{3}{*}{6.1} & \multirow{3}{*}{$46.29^{\circ} \mathrm{N}$} & \multirow{3}{*}{$13.20^{\circ} \mathrm{E}$} & \multirow{3}{*}{ BRE } & \multirow{3}{*}{30.0} & Z & 0.84 \\
\hline & & & & & & & & & & $\mathrm{N}$ & 1.13 \\
\hline & & & & & & & & & & $\mathrm{E}$ & 1.20 \\
\hline & \multirow{3}{*}{3} & & & & & & & & & Z & 0.71 \\
\hline & & $\begin{array}{l}\text { Montenegro } \\
\text { (afterskock) }\end{array}$ & $1979-05-24$ & $17: 23: 18$ & 6.3 & $42.23^{\circ} \mathrm{N}$ & $18.76^{\circ} \mathrm{E}$ & KOTCZ & 23.0 & $\mathrm{~N}$ & 1.12 \\
\hline & & & & & & & & & & E & 1.52 \\
\hline & & & & & & & & & & Z & 1.35 \\
\hline & 1 & New & 2016-02-14 & 00:13:43 & 5.7 & $43.30^{\circ} \mathrm{S}$ & $172.45^{\circ} \mathrm{E}$ & HPSC & 4.0 & $\mathrm{~N}$ & 1.79 \\
\hline & & & & & & & & & & E & 1.80 \\
\hline & & & & & & & & & & Z & 1.64 \\
\hline PGA2 & 2 & Campano & $1980-11-23$ & $18: 34: 52$ & 6.9 & $40.90^{\circ} \mathrm{N}$ & $15.44^{\circ} \mathrm{E}$ & STR & 16.0 & $\mathrm{~N}$ & 1.63 \\
\hline & & & & & & & & & & E & 1.50 \\
\hline & & & & & & & & & & Z & 1.39 \\
\hline & 3 & Spitak & $1988-12-07$ & $07: 41: 24$ & 6.8 & $40.91^{\circ} \mathrm{N}$ & $44.25^{\circ} \mathrm{E}$ & HRS & 36.0 & $\mathrm{~N}$ & 1.79 \\
\hline & & & & & & & & & & E & 1.77 \\
\hline & & & & & & & & & & Z & 3.04 \\
\hline & 1 & Brea. CA & 2014-03-29 & 04:09:42 & 5.1 & $33.932 \mathrm{~N}$ & $117.916 \mathrm{~W}$ & 13879 & 8.4 & $\mathrm{~N}$ & 2.87 \\
\hline & & & & & & & & & & E & 2.29 \\
\hline & & & & & & & & & & Z & 4.23 \\
\hline PGA3 & 2 & Montenegro & 1979-04-15 & $18: 19: 41$ & 7.0 & $41.98^{\circ} \mathrm{N}$ & $18.98^{\circ} \mathrm{E}$ & BUD & 24.0 & $\mathrm{~N}$ & 2.70 \\
\hline & & & & & & & & & & E & 2.30 \\
\hline & & & & & & & & & & $Z$ & 2.08 \\
\hline & 3 & $\begin{array}{c}\text { Campano } \\
\text { Lucano }\end{array}$ & $1980-11-23$ & $18: 34: 52$ & 6.9 & $41.02^{\circ} \mathrm{N}$ & $15.12^{\circ} \mathrm{E}$ & BGI & 32.0 & $\mathrm{~N}$ & 2.29 \\
\hline & & & & & & & & & & E & 3.18 \\
\hline & & & & & & & & & & $Z$ & 1.71 \\
\hline & 1 & $\begin{array}{c}\text { New } \\
\text { Zealand }\end{array}$ & $2011-12-23$ & 02:18:03 & 5.9 & $43.31^{\circ} \mathrm{S}$ & $172.45^{\circ} \mathrm{E}$ & LPCC & 10.0 & $\mathrm{~N}$ & 3.78 \\
\hline & & & & & & & & & & E & 3.32 \\
\hline & & & & & & & & & & $Z$ & 1.97 \\
\hline PGA4 & 2 & Tabas & 1978-09-16 & $15: 35: 57$ & 7.3 & $33.36^{\circ} \mathrm{N}$ & $57.42^{\circ} \mathrm{E}$ & DAY & 11.0 & $\mathrm{~N}$ & 3.83 \\
\hline & & & & & & & & & & E & 3.51 \\
\hline & & & & & & & & & & $Z$ & 3.23 \\
\hline & 3 & $\begin{array}{c}\text { New } \\
\text { Zealand }\end{array}$ & $2011-02-22$ & 01:50:29 & 5.6 & $43.35^{\circ} \mathrm{N}$ & $172.38^{\circ} \mathrm{E}$ & CBGS & 7.0 & $\mathrm{~N}$ & 3.46 \\
\hline & & & & & & & & & & E & 4.38 \\
\hline & & & & & & & & & & $Z$ & 2.43 \\
\hline & 1 & $\begin{array}{l}\text { New Zealand } \\
\text { (Seddon) }\end{array}$ & 2013-08-16 & 02:31:05 & 6.6 & $41.44^{\circ} \mathrm{S}$ & $174.09^{\circ} \mathrm{E}$ & WDFS & 10.0 & $\mathrm{~N}$ & 3.82 \\
\hline & & & & & & & & & & E & 5.03 \\
\hline & & & & & & & & & & $Z$ & 1.88 \\
\hline PGA5 & 2 & $\begin{array}{c}\text { Friuli } \\
\text { (aftershocks) }\end{array}$ & 1976-09-15 & 03:15:19 & 6.1 & $46.26^{\circ} \mathrm{N}$ & $13.43^{\circ} \mathrm{E}$ & FOG & 18.0 & $\mathrm{~N}$ & 4.82 \\
\hline & & & & & & & & & & E & 4.96 \\
\hline & & & & & & & & & & Z & 2.41 \\
\hline & 3 & Erzican & 1992-03-13 & $17: 18: 40$ & 6.8 & $39.72^{\circ} \mathrm{N}$ & $39.63^{\circ} \mathrm{E}$ & GUK & 13.0 & $\mathrm{~N}$ & 4.79 \\
\hline & & & & & & & & & & E & 4.78 \\
\hline
\end{tabular}




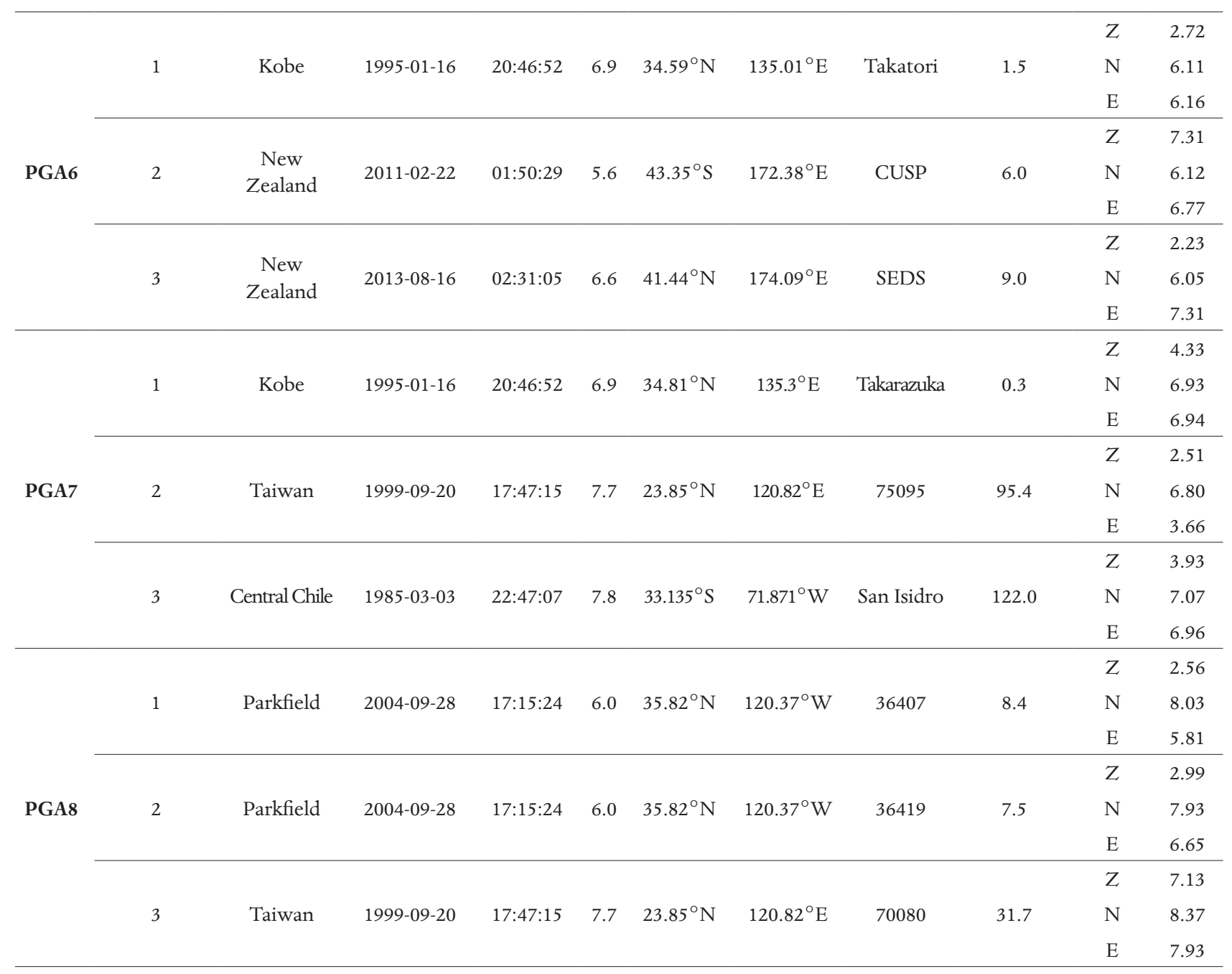

Table 1. Parameters of 24 earthquake strong motion records. The records were selected based in PGA in the horizontal components for eight PGA target values indicated in the first column. There are three records for each PGA-range.

first to third quartile of MDVs. At PGA $1.0 \mathrm{~m} / \mathrm{s}^{2}$ no toppling occurs at any of the tested frequencies. This also holds for $2.0 \mathrm{~m} / \mathrm{s}^{2}$ in case of PW1 and for all walls at frequencies of 2.5 and $3.0 \mathrm{~Hz}$. The patterns show that the RBW often completely topples while the polygonal walls and ITW only partially collapse. As expected, all wall types are least vulnerable when the motion is parallel to the wall trend at $90^{\circ}$ and $270^{\circ}$.

Some of the MDV-patterns in Figure 8 are not perfectly symmetric with respect to the azimuth in which the ground motion is applied. For example in case of the PW1 at a frequency of $1.5 \mathrm{~Hz}$ and PGA of $6.0 \mathrm{~m} / \mathrm{s}^{2}$ the wall partially collapses for the $180^{\circ}$ direction, but not for the $0^{\circ}$ direction. At frequency-PGA combinations where the transition from survival to collapse or between the two failure modes occurs, the model tends to a chaotic behavior; i.e., small changes in the boundary conditions have a large influence on the reaction of the wall. Such behavior with almost unpredictable outcome was also described by Hinzen [2010] when he studied collapsing columns under earthquake load with small fractions of noise added to the ground motions.

As already visible in the screen shots (Figure 6) and the box-plots (Figure 8), an increasing PGA is necessary to topple the walls when the frequency of the ground motion grows. This in general applies to all four wall models. As expected, the number of collapses decreases significantly with decreasing $\mathrm{h} / \mathrm{w}$-ratios. On the other hand, due to the increase in inertial forces of the larger blocks, W2 and W3 models show increasing internal block displacements compared to $\mathrm{W} 1$; the corresponding plots for $\mathrm{h} / \mathrm{w}$-ratios $\mathrm{W} 2$ and W3 are shown in Figures S1 and S2 (available in the electronic supplements to this article).

PGA has traditionally been widely used in earthquake engineering to characterize the severity of ground motions. However, in practice the importance of PGA alone to quantify the damage potential of the ground motion may have been overemphasized [Bozorgnia and Bertero 2004]. In order to examine potential relation between the behavior of the wall 


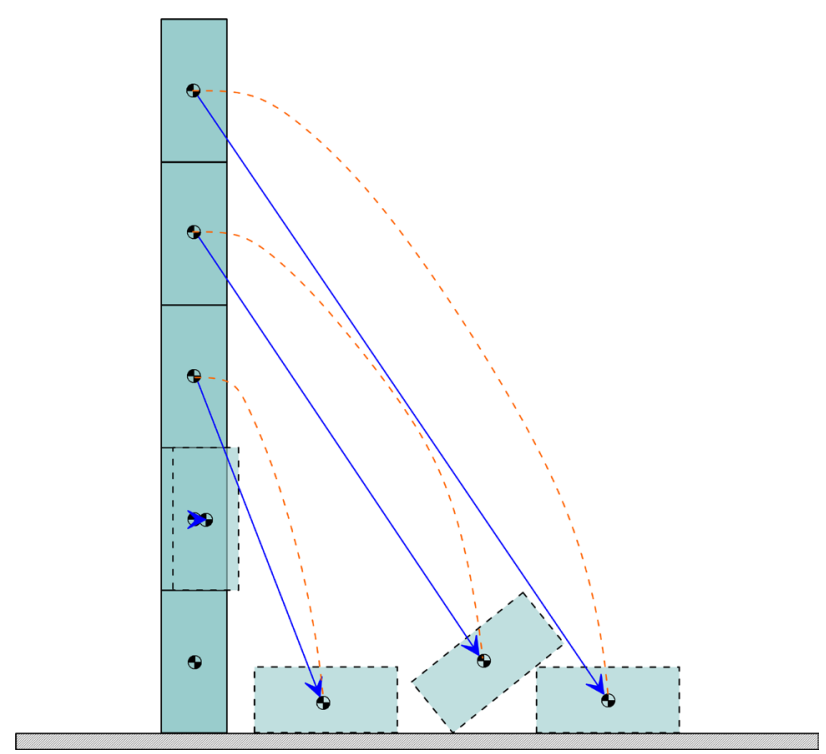

Figure 7. Schematic explanation of the modulus of the displacement vector (MDV) used to quantify the deformation of walls. The blocks with the dashed outline show the position at the end of the experiment, while the continuously outlined blocks show the starting position. Dashed red lines indicate the trajectories of dislocated blocks and the length of the blue vectors give the MDV.

models (internal displacement of blocks and toppling behavior) we plotted the median MDVs from all experiments with respect to a number of parameters
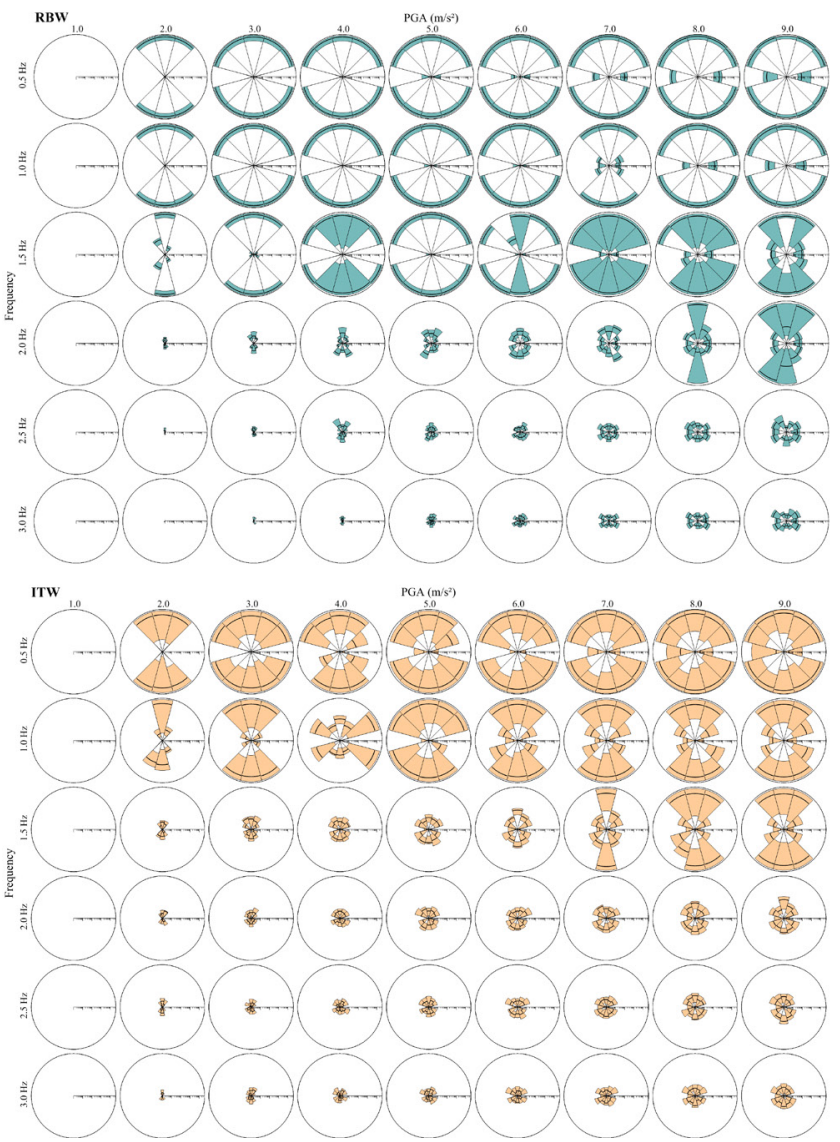

used in engineering seismology to characterize strong ground motions including PGA, PGV, PGD, PGV/ PGA-ratio, root-mean-square of acceleration, velocity, and displacement, Arias intensity, characteristic intensity, specific energy density, cumulative absolute velocity, acceleration and velocity spectrum intensity, Housner intensity and predominant period [Kramer 1996]. Figure 9 shows some examples where the two distinct clusters of median MDVs resemble the walls that survived the test (cluster of low MDVs) and walls that toppled (cluster of high MDVs). For the PGA plot, the two clusters overlap over a broad range of PGA values; this in turn means that a toppled wall alone in archaeoseismology is not a suitable indicator of an 'archaeo-acceleration'. On the other hand, parameters with the unit of length (PGD, RMS displacement, velocity spectrum intensity, and Housner intensity) and to some degree the plot with the predominant period show rather well sorted median MDVs and provide a rough determination of threshold value above which the wall will collapse. This observation, as shown by the RBW in Figure 9, also holds for the other wall types.

The best separation between surviving and toppling walls was found when the MDVs are correlated

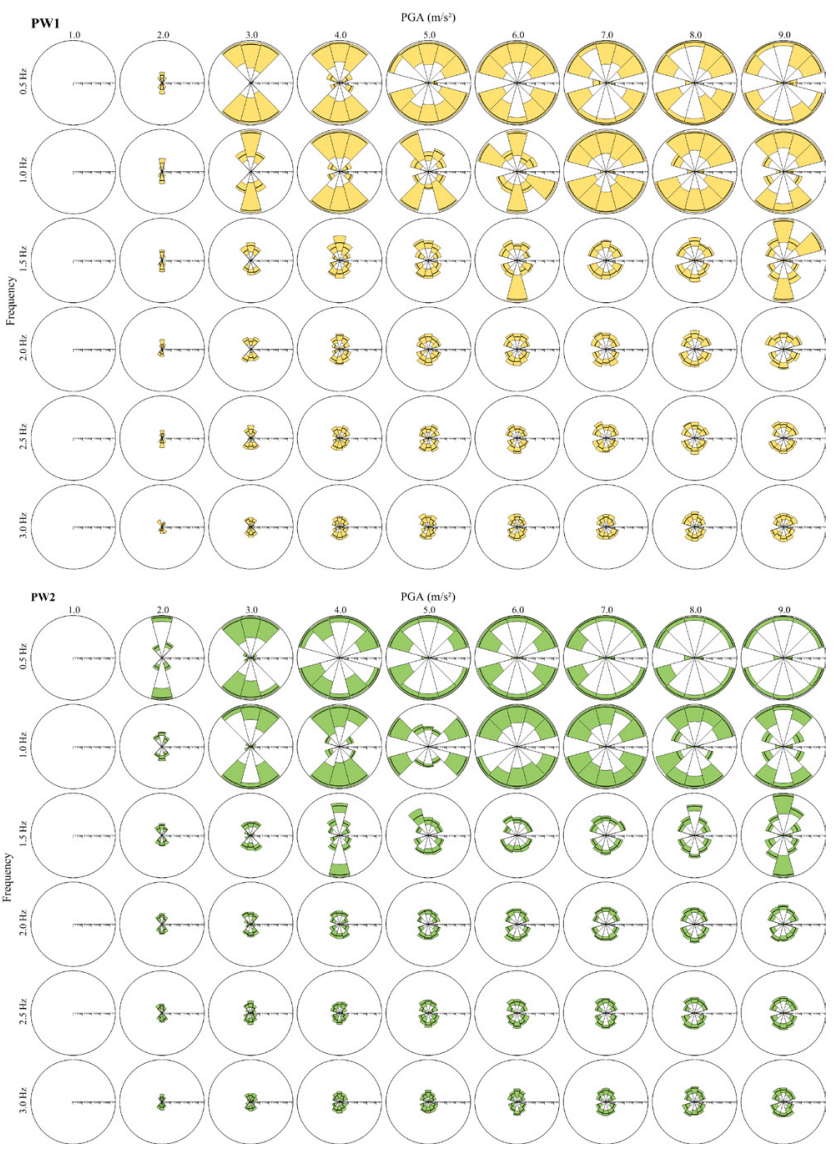

Figure 8. Results of numerical tests with four wall types with an h/w-ratio of 10.7 (W1). The heavy black lines in the polar box-plots give the median values of the MDVs for 12 directions of ground motion in increments of $30^{\circ}$. The colored MDV-ranges reach from the first (inner) to the third (outer) quartile of the MDV distribution. The logarithmic radius scale ranges from 0.0001 to $4.0 \mathrm{~m}$ for all graphs. 

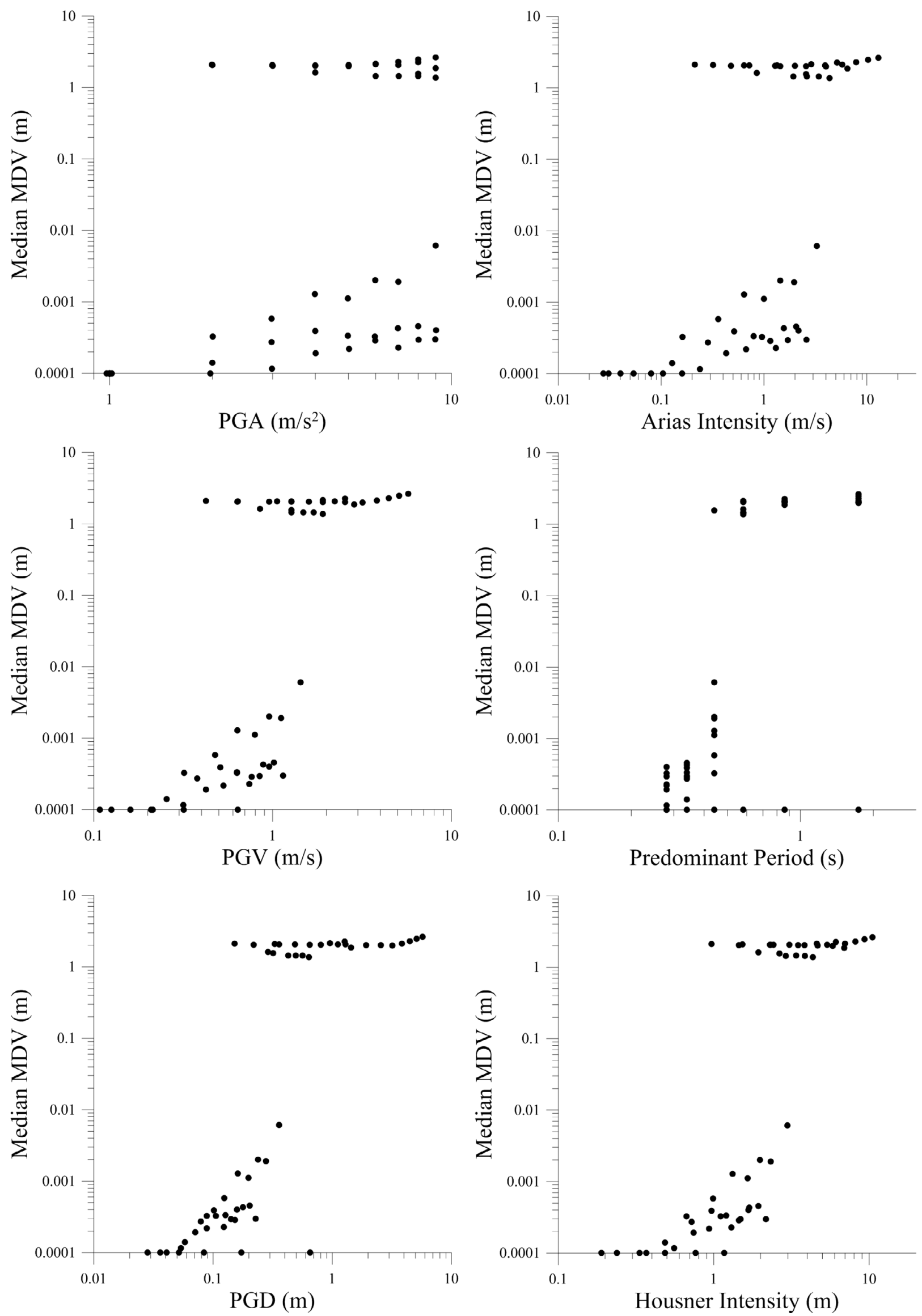

Figure 9. Median values of the modulus of the displacement vectors (MDV) of all blocks of the RBW during the numerical tests with Cycloidal pulses with respect to six engineering seismological parameters including peak ground acceleration, velocity and displacement (PGA, PGV, PGD), Arias intensity, predominant period and Housner intensity. The data are from the test with the RBW with $\mathrm{h} / \mathrm{w}$-ratio of 10.8 for a ground motion towards $0^{\circ}$. 


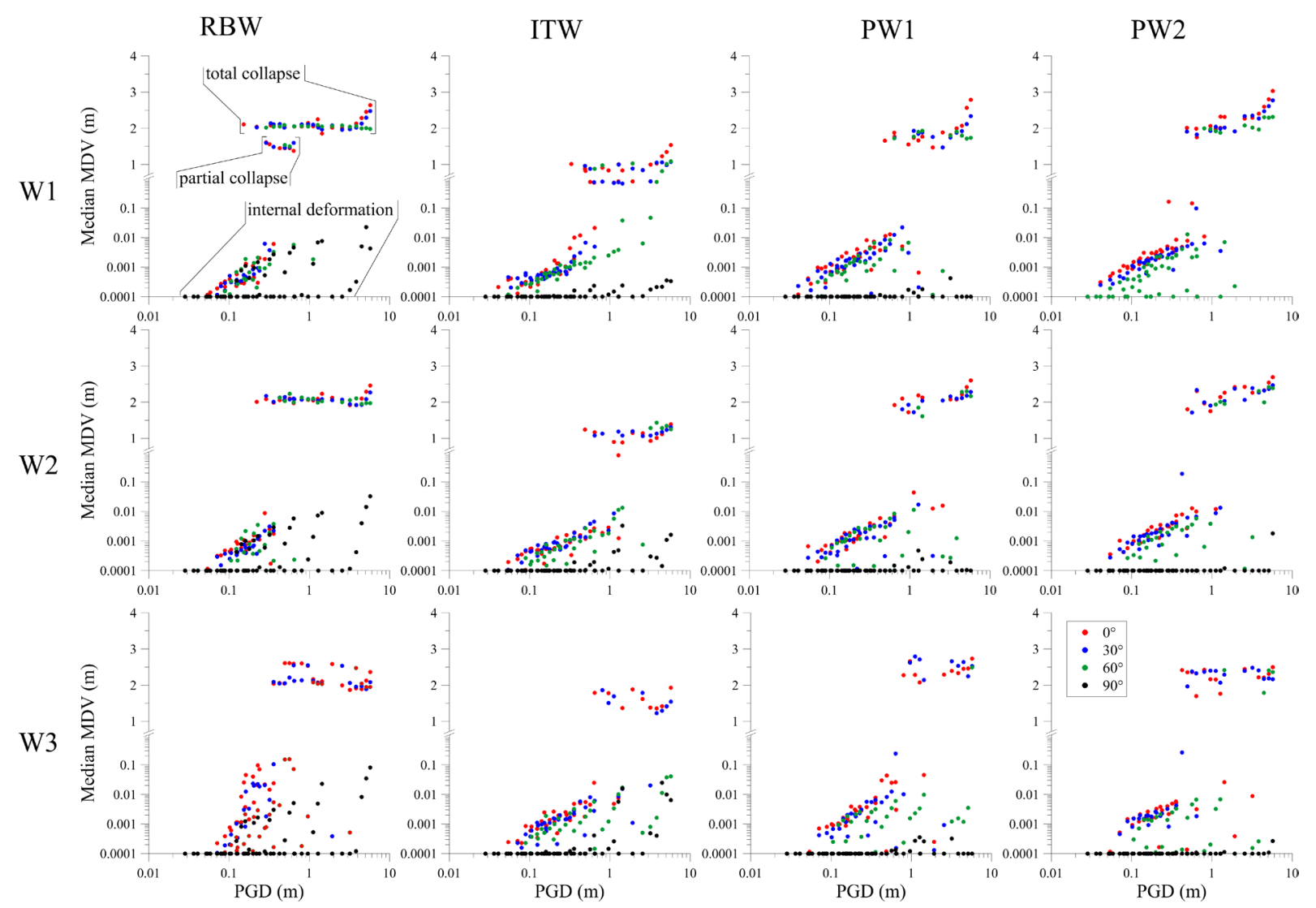

Figure 10. Median values of the modulus of the displacement vectors (MDV) of all blocks during the numerical tests with cycloidal pulses (Figure 8) with respect to PGD for the four wall geometries and three h/w-ratios (see legend) and orientation of the ground motion oriented at $0^{\circ}$ (orthogonal to the wall trend), $30^{\circ}, 60^{\circ}$, and $90^{\circ}$ (parallel to the wall trend); symbols are explained in the legend. The scale of the median MDVs has a breakpoint at $0.8 \mathrm{~m}$, below for the internal deformations it is logarithmic, and above for the (partial) collapse it is linear. In the top left graph ranges corresponding to total collapse, partial collapse, and internal deformation are marked.

with the PGD. The toppling cases at the lower PGD values which overlap with the surviving walls are mainly those to the second failure mechanism.

Figure 10 shows that the threshold at which the toppling starts increases with decreasing $\mathrm{h} / \mathrm{w}$-ratio and is lower for the RBW than the three other models. Further, both clusters of the surviving and toppled walls generally show an increase of the MDVs with increasing PGD. For cases of total collapse there is an increase of the median MDVs above PGDs of $\sim 1.0 \mathrm{~m}$ indicating a further throw of the blocks during the toppling process. This effect is strongest with a ground motion orthogonal to the wall and decreases with increasing azimuth. The significantly lower median MDVs for the ITW indicate that here partial collapses are more frequent.

These findings show that in realistic archaeoseismic models of certain (simple) wall structures, in addition to the result indicating whether the toppling PGD threshold was exceeded or not, a rough estimate of the PGD might be possible. Also, the internal block displacement correlates with an increase of the ground motion. This confirms the approach of a field case by presented by Caputo et al. [2010] who examined internal block displacements of the scene building of the ancient Larissa Theatre in Greece.

The reaction of the walls to 'real' earthquake ground motions is shown in Figure 11 for the largest $\mathrm{h} / \mathrm{w}$-ratio (W1). (For results with $\mathrm{h} / \mathrm{w}$-ratios W2 and W3, see Figures S9 and S10 available in the electronic supplement to this article). The polar boxplots show the variability of results when compared with the simply structured analytic ground motions in Figure 8. The thin colored ring at high MDV levels for the RBW indicate the more frequent total collapses than for the other wall types. An example is the third ground motion at $5.0 \mathrm{~m} / \mathrm{s}^{2}$ PGA. Here the RBW totally collapses for each of the 12 different azimuths at which the ground motion is applied. ITW on the other hand shows partial collapse for all directions except $120^{\circ}$ where it survives, and both polygonal walls survive for several azimuths. The earthquake tests show again that PGA is not recoverable with certainty; even at PGAs above $7 \mathrm{~m} / \mathrm{s}^{2}$ some models survive while they topple at much smaller PGAs. 


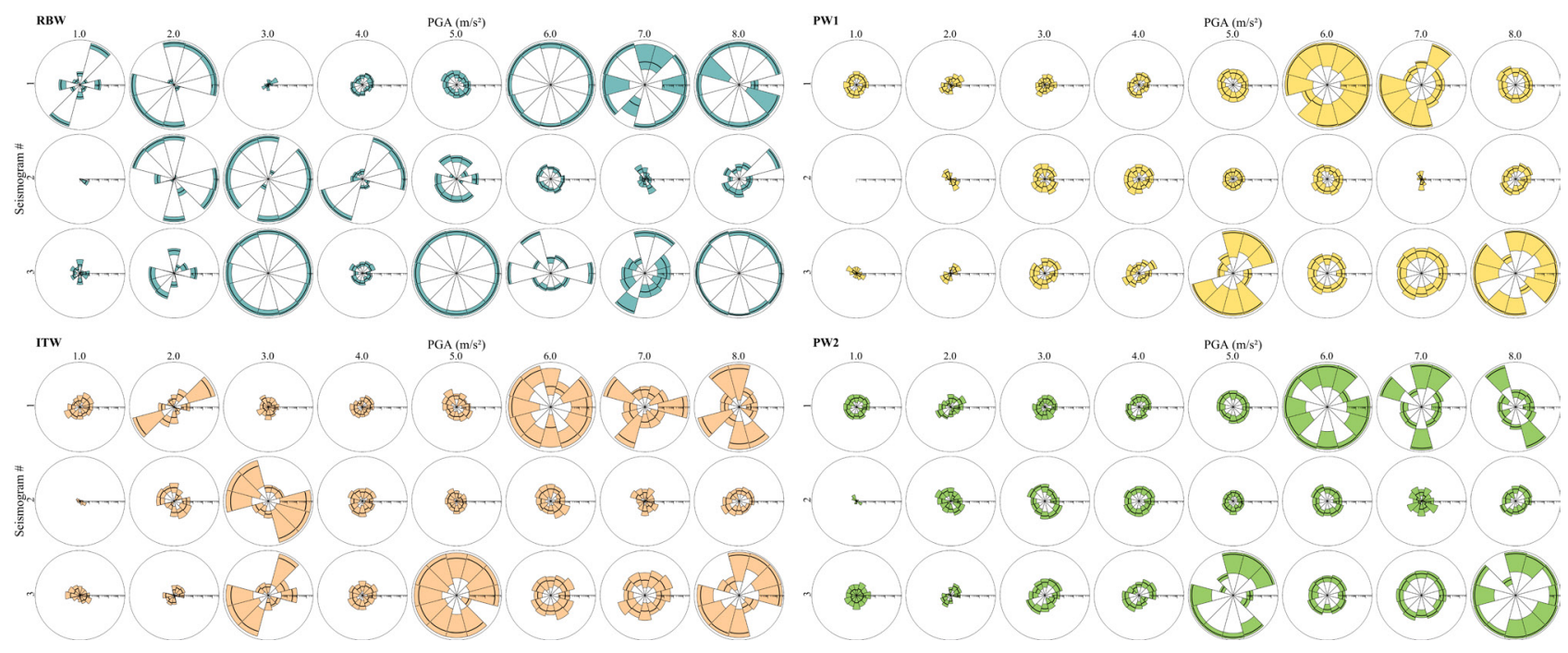

Figure 11. Median values of the modulus of the displacement vectors (MDV) of all blocks during numerical tests with the 24 recorded earthquake ground motions listed in Table 1 plotted as polar boxplots. The colored area gives the range of MDV values between the 1st and 3 rd quartile in steps of $30^{\circ}$ of azimuth with which the horizontal ground motion components were rotated. The heavy black lines give the corresponding median values of MDVs. The logarithmic radius scale ranges from 0.0001 to $4.0 \mathrm{~m}$ for all graphs. Same color code for the different wall types is used as in Figure 1.
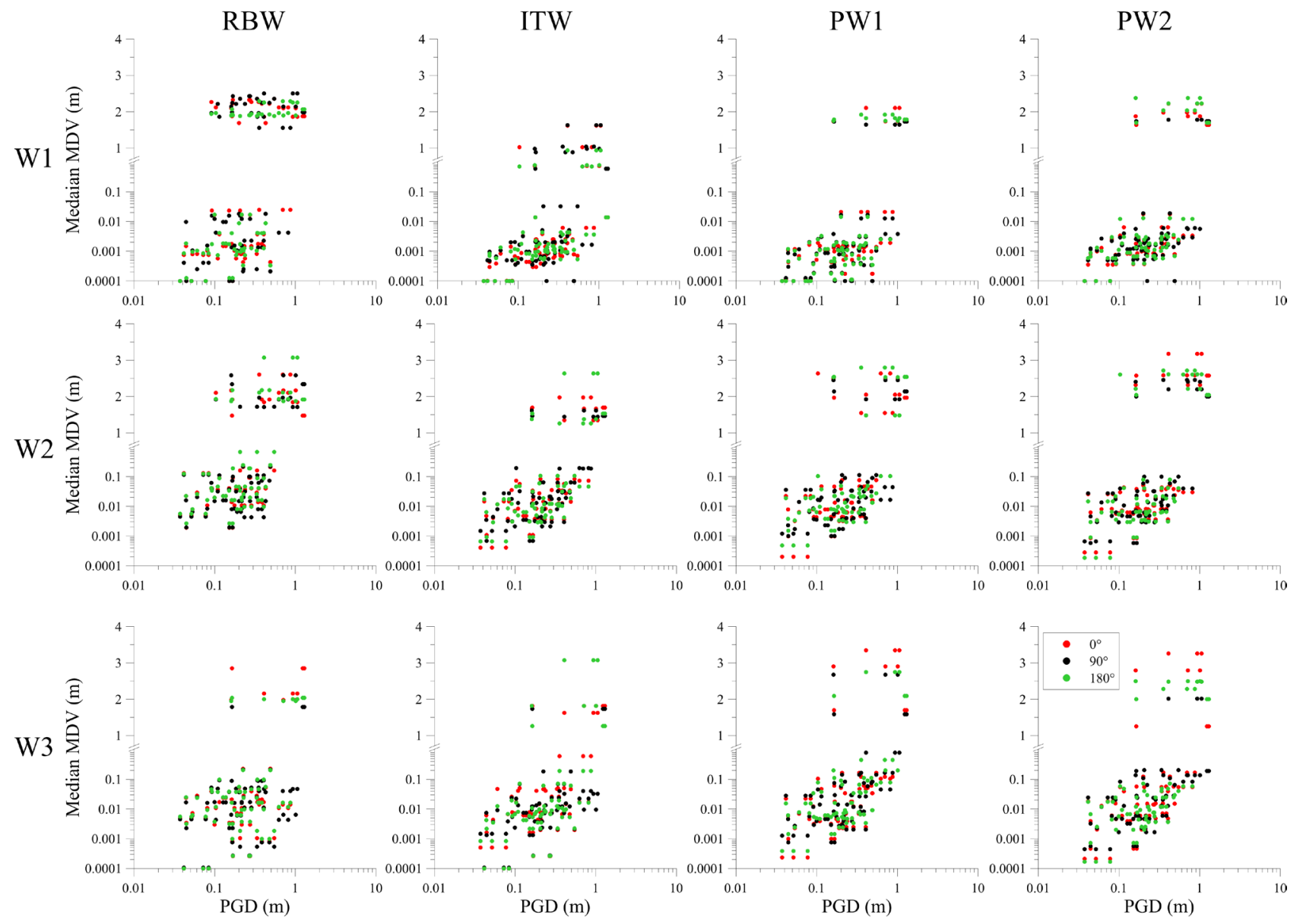

Figure 12. Median values of the modulus of the displacement vectors (MDV) of all blocks during the numerical tests with the 24 earthquake ground motion records (Figure 4) with respect to PGD for the four wall geometries and three h/w rations (see legend) and orientation of the ground motion oriented at $0^{\circ}$ (N-component orthogonal to the wall trend), $90^{\circ}$ (N-component parallel to the wall trend), and $180^{\circ}$; symbols are explained in the legend. The scale of the median MDVs has a breakpoint at $0.8 \mathrm{~m}$, below for the internal deformations it is logarithmic, and above for the (partial) collapse it is linear. 
Taken together with the results for the other two $\mathrm{h} / \mathrm{w}$-ratios (Figures S9 and S10, available in the electronic supplement to this article), the test results with the recorded ground motion examples show a higher chance of the RBW to topple than the other walls, particularly the ITW.

It is evident that the results from the tests with the recorded ground motions are more complex than those for simply structured cycloidal pulses. This result is not surprising, considering that the Cycloidal pulses contained no vertical ground motion and only one cycle. Figure 12 shows the median MDVs with respect to the largest of the PGDs of all three components for the recorded earthquakes for selected angles of orientation. Here, it is much harder to determine a PGD threshold for the collapsing than for the cycloidal pulses. Most complete collapses occur for RBW with W1 and W2, and for ITW most collapses are only partial as indicated by the overall smaller median MDVs. In comparison with the Cycloidal pulse excitation, internal deformations below $1 \times 10^{-3}$ $\mathrm{m}$ are seldom observed, which is an effect of the high frequency content in the earthquake records that is absent in the analytic signals.

The overall ratio of collapsed walls to those which survived is summarized in Figure 13. In all six cases (three $\mathrm{h} / \mathrm{w}$-ratios for Cycloidal pulses and earthquake records) the RBW is more vulnerable than the other three wall types. Due to its regular internal design, the median MDV values show a narrow distribution in most cases. Even though the number of partially and totally collapsed cases is slightly smaller for PW1 than for the ITW, the overall performance of ITW is better for W1 and W2 for both Cycloidal pulses and earthquake excitation, most collapses are only partial and not total as is the case for the other walls. For W3, this difference flattens out.

\section{Discussion and conclusions}

In order to study the behavior of discrete element models of four walls with different internal geometries, we made more than 11,200 numerical tests including analytic ground motion signals and measured earthquake strong motion records. The ground motions were selected to cover PGAs ranging from 1.0 to $9.0 \mathrm{~m} / \mathrm{s}^{2}$ with dominating frequencies from 0.5 to $3 \mathrm{~Hz}$. For cases of simple structured ground motions (Cycloidal pulses) and earthquake excitation, the rectangular block wall was more vulnerable than the polygonal walls. For larger height-to-width ratios, the Inca type wall showed a clear tendency to partial col- lapse, while the other three types totally collapsed.

Particularly in case of excitation with strong motion records, the rectangular block wall proved more vulnerable than the polygonal walls. However, changes in the design of wall geometries might lead to different results and it must be kept in mind that rectangular blocks in reality were often secured by clamping mechanisms or by the use of mortar. The excitation with the cycloidal pulses showed the frequency dependence of the wall behavior. This indicates that ground motions with strong site effects and amplified amplitudes in narrow frequency bands have a strong influence on the outcome. A full analysis of site effect influence would be worth its on study. Another limiting point of this study is the sole use of free-standing walls without corners. Such constructions are rare in archaeoseismology where most walls are parts of buildings with at least four corners and also usually include wall openings (doors and/or windows). As early as the $19^{\text {th }}$ century, Mallet [1862] pointed out the increased vulnerability of wall corners due to differential motions with the consequence of corner expulsions. However, our main interest was the influence of the block shape on the dynamic behavior and a higher vulnerability of the ends of the wall models was also seen in our tests (Figure 6, and Figures S1 and S2 available in the electronic supplement to this article).

Previous archaeoseismic studies have shown that cases exist where real polygonal walls with less ideal geometries than our models suffered severe damage. Yerli et al. [2010] report damage to the northern temple wall of Pinara in Lycia. This wall is a combination of polygonal Hellenistic building technique and rectangular-shaped Roman masonry which indicates that the damaged Hellenistic wall was restored during the Roman period. However, the severe damage, dislocation, and rotation of both types of masonry show that this building suffered from later earthquakes as well [Yerli et al. 2010]. As a consequence, both sections suffered a comparable degree of damage indicating that here the polygonal technique was not of advantage. Galadini et al. [2010] examined a late antique earthquake in Alba Fucens, Central Italy. They state that wall collapse is also mentioned in the reports of the July 18 and 21, 1951 earthquakes which involved walls of polygonal blocks, i.e. heavy and solid structures.

Even though the RBW model is more vulnerable in our tests, the experience of observing and interpreting a large number of numeric experiments, we conclude that the interpretation of the evolution of building techniques in terms of earthquake resilience 


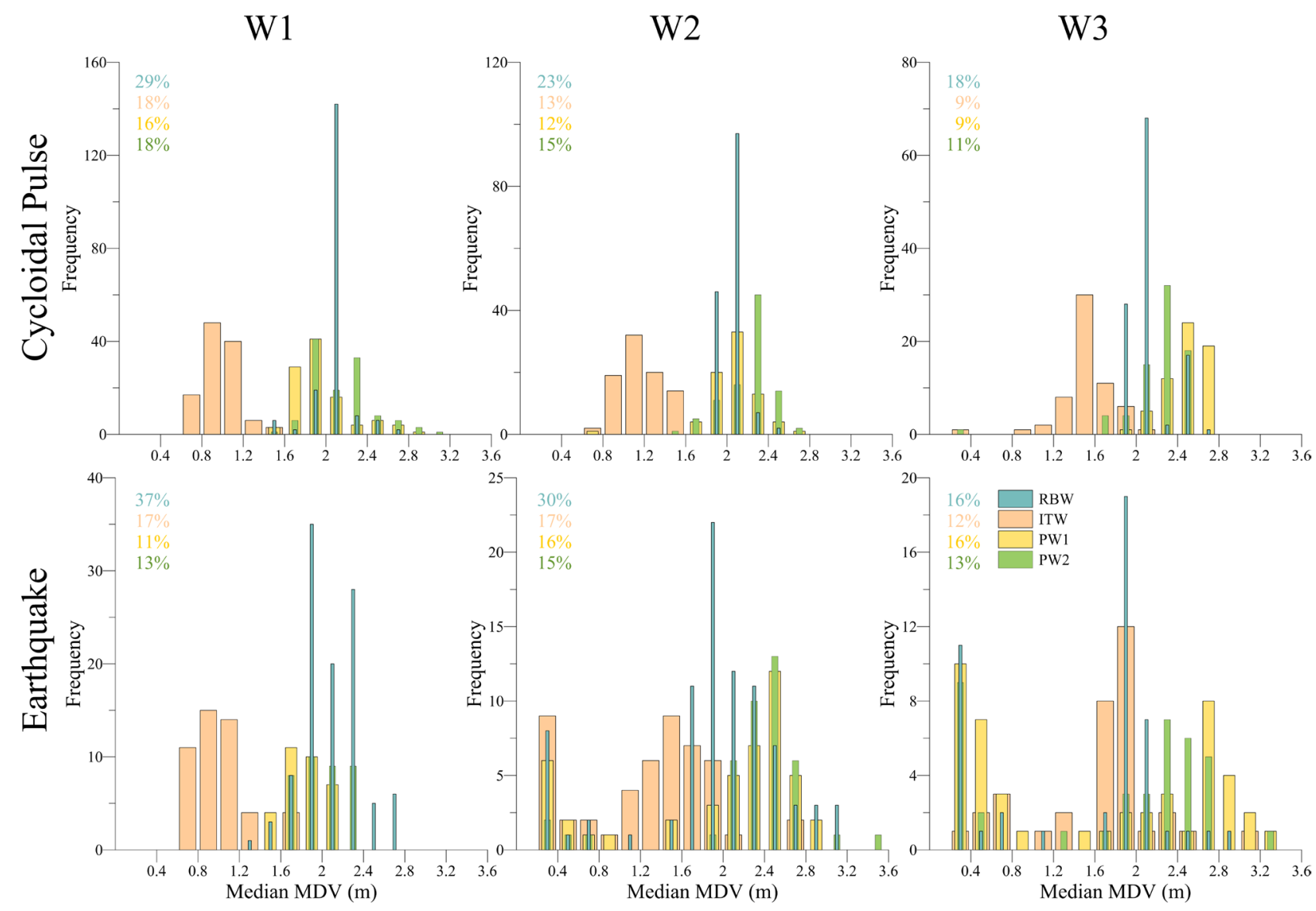

Figure 13. The histograms show the distribution of median MDV values for all test calculations with MDVs larger than $0.2 \mathrm{~m}$ (partial or total collapse). The wall types are given by the color of the bars as shown in the legend in the lower right graph. W1, W2, and W3 are the cases of $\mathrm{h} / \mathrm{w}$-ratios of $10.8,7.2$, and 5.4, respectively. Graphs in the top row summarize results of the tests with Cycloidal pulses; those in the bottom row the tests with earthquake signals. Colored numbers in the top left of each graph give the percentage of (partially-) toppled walls of 648 tests for the Cycloidal pulses and 288 for earthquake excitation.

should be made with great care. Even in high seismicity regions devastating earthquakes are not frequent enough to provoke major changes in engineering within one generation of builders. Written sources communicating such experiences from one generation to the next are not known to us. As technical evolution in antiquity was mainly by trial and error, it would have taken several earthquake-rebuilding cycles before a successful adaption of constructions would have been possible.

Rather than concluding that walls were constructed with the goal of earthquake resistance, other reasons must be considered to have led to polygonal wall designs. One simple reason might be esthetics; people just liked the appearance of polygonal patterns of various forms. Some of the persisting ancient examples are still beautiful by modern standards. Another reason could be one of economics. In ancient times, quarrying was done by costly amounts of manual labor. Depending on the type of rock and its depositional situation, quarrying produces blocks of various sizes and shapes. In order to construct a wall of regular rectan- gular blocks, all quarried rocks below a certain threshold size are unusable and constitute wasted material. It is not by chance that this technique was preferably used only for important, mostly official buildings. For polygonal walls, a larger variety of block sizes and shapes remains usable (Figure 2) and therefore more economic. Impressing spectators was surely another reason, the efforts driven either by religious or secular needs. The huge cyclopean fortification walls used by the Mycenaean in Mycenae, Tiryns [Maran 2010, Hinzen et al. 2016] and Midea found continuation in constructions in Italy. In addition to defense purposes, these walls were built to impress forcibility upon any potential aggressor or the native peasants. That the intention of impressing men or gods was often a motivation for the large building efforts was mentioned by Adam [1994]. He further states that, in polygonal walls for reasons of (static) stability, the random joints are replaced at corners and door jambs by larger blocks which are laid in regular courses to keep the other courses from slipping. All these reasons seem as likely to us as the attempt to establish earthquake resilient 
techniques as a primary or even as a secondary cause. Combinations of these reasons with regionally different emphases probably also apply.

In conclusion, with our simple wall models we see a higher earthquake resistance of polygonal or Inca-type walls compared to rectangular block walls (without clamping) with the application of selected sample earthquake ground motions. The height to width ratio parameter has an influence at least as important on the stability as the block geometry. Torres [2014] pointed out that constructions in the pre-Hispanic Peruvian Andes gained their stability from $\mathrm{h} / \mathrm{w}$-ratios of 2 to 3 . For simple ground motion pulses, the maximum displacement of the ground determines whether a wall topples. Unfortunately, peak ground acceleration cannot be back-calculated from a toppled wall with certainty. But even for simply structured ground motions, the ground motion azimuth with respect to the wall trend remains a further unknown in most archaeoseismic cases and hampers back-calculation of ground motion parameters. Even a motion with 10-fold amplitude might not topple a wall if it is applied parallel to the wall compared to an excitation orthogonal to the wall. Internal deformation in the form of differential block sliding increases with increasing strength of ground motions and high frequency content. However, as already shown by Caputo et al. [2010], care must be taken to factor in the appropriate friction response of the wall joints.

We hope the results of this study help to improve the process of deduction of ground motion parameters for toppled walls documented in archaeological excavations. However, we should emphasize that conclusions about ancient ground motions from such ruins should be made with great caution. Thorough individual modeling of certain wall types is necessary, ideally coupled with actual field cases to provide results that are more complex than pure laboratory experiments. Despite these limitations, the results show that persisting archaeological monuments, similar to precariously balanced rocks, can be used as indicators for ground motion parameters that have not been exceeded since they reached their final and/or contemporary position.

\section{Data and Resources}

Strong motion data used in the simulations were retrieved from the Center for Engineering Strong Motion Date (CSEMD, http://www.strongmotioncenter.org/, last accessed May 2016) and the European Strong-Motion Database (ESD, http://www.isesd.
hi.is/ESD_Local/, last accessed May 2016). Discrete element calculations were made with the UNITY (Unity Technologies Ltd., v. xxx) under use of the physics engine PhysX (Nvidia Corporation, v xxx). Photo credit of the Inca-type wall is to ITW: Martin St-Amant Wikipedia - CC-BY-SA-3.0, all other photos were taken by the first author. Part of the strong motion data processing was made with SeismoSignal (http:/ / www. seismosoft.com, last accessed May 2016).

Acknowledgements. We thank H. Kehmeier and I. Schwellenbach for the efforts to create some early versions of the discrete element models, G. Schweppe helped to solve software problems, K. Kemna assisted with some data handling. We are grateful to S.K. Reamer for comments on an early version of the manuscript and editing of the final submission. Two anonymous peers helped to improve the paper during the review process and we thank the editors for handling the special volume.

\section{Referencesc}

Adam, J.-P. (1994). Roman building, materials and techniques, Routledge, London and New York, 360 pp.

Ambraseys, N.N. (1973). Earth sciences in archaeology and history, Antiquity, 47, 229-230.

Ambraseys, N.N. (2006). Earthquakes and archaeology, Journal of ArchaeologicalScience, 33, 1008-1016.

Ambraseys, N. and I.N. Psycharis, (2012). Assessment of the long-term seismicity of Athens from two classical columns, Bulletin of Earthquake Engineering, 10, 1635-1666.

Bozorgnia, Y. and Bertaro, V.V. (edts) (2004). Earthquake engineering: from engineering seismology to performance-based engineering, CRC Press, Boca Raton, 1150 pp.

Brune, J. N. (1996). Precariously balanced rocks and ground motion maps for southern California, Bull. Seismol. Soc. Am., 86, 43-54.

Brune, J.N. and J.W. Whitney (1992). Precariously balanced rocks with rock varnish-Paleoindicators of maximum ground acceleration? Seismological Research Letters, 63, 21.

Caputo, R., K.-G. Hinzen, D. Liberatore, S. Schreiber, B. Helly and A. Tziafalias (2010). Quantitative archaeoseismological investigation of the Great Theatre of Larissa, Greece, Bull Earthquake Engineering, 9, 347-366, DOI 10.1007/s10518-010-9206-6.

Cucci, L. and A. Tertulliani (2011). Clues for a relation between rotational effects induced by the Mw 6.3 2009 L'Aquila (Central Italy) earthquake and site and source effects, Bull. Seismol. Soc. Am., 101, 1109-1120.

Galadini, F. and P. Galli (2001). Archaeoseismology in Italy: case studies and implications on long-term 
seismicity, Journal of Earthquake Engineering, 5, 35-68.

Galadini, F., K.-G. Hinzen and S. Stiros (2006). Archaeoseismology: methodological issues and procedure, Journal of Seismology, 10, 395-414.

Galadini, F., E. Ceccaroni and E. Falcucci (2010). Archaeoseismological evidence of a disruptive Late Antique earthquake at Alba Fucens (central Italy), Bollettino di Geofisica Teorica ed Applicata, 51, 143-161.

Grünthal, G. (1993). European macroseismic scale 1992, Centre Européen de Géodynamique et de Séismologie, Luxembourg, 79 pp.

Hinzen, K.-G. (2005). The use of engineering seismological models to interpret archaeoseismological findings in Tolbiacum, Germany: a case study, Bulletin Seismological Society of America, 95, 521-539.

Hinzen, K.-G. (2009a). Impact patterns of toppled walls, Seismological Research Letters, 80, 382.

Hinzen, K.-G. (2009b). Dynamic response of simple structures, in, Archaeoseismology and Palaeoseismology, in the Alpine-Himalayan Collisional Zone R. Pérez-López, C. Grützner, J. Lario, K. Reicherter and P.G. Silva (edts.), Baelo Claudia, Cadiz Spain, 47-49.

Hinzen, K.-G. (2009c). Simulation of toppling columns in archaeoseismology, Bull. Seism. Soc. Am., 99, 2855-2875.

Hinzen, K.-G. (2010). Sensitivity of earthquake toppled columns to small changes in ground motion and geometry, Israel Journal of Earth Sciences, 58, 309-326, doi: 10.1560/IJES.58.3-4.309.

Hinzen, K.-G., S. Schreiber and B. Yerli (2010). The Lycian Sarcophagus of Arttumpara, Pinara, Turkey: Testing Seismogenic and Anthropogenic Damage Scenarios, Bull. Seism. Soc. Am., 100, 3148-3164.

Hinzen, K.-G., L. Cucci and A. Tertulliani (2013). Rotation of objects during the 2009 L'Aquila earthquake analyzed with 3D laser scans and discrete-element models. Seismological Research Letters, 84, 745751, doi: $10.1785 / 0220130010$.

Hinzen, K.-G., H. Hinojosa-Prieto and T. Kalytta (2016). Site effects in archaeoseismic studies at Mycenaean Tiryns and Midea, Seismological Research Letters, 87, 751-764.

Housner, G.W. (1963). The behavior of inverted pendulum structures during earthquakes, Bull. Seismol. Soc. Am. 53, 403-417.

Kamei, R. and Y. H. Hatzor (2007). Numerical analysis of block stone displacements in ancient masonry structures: A new method to estimate historic ground motions, Int. J. Numer. Anal. Meth. Geomech., 32, 1321-1340.

Karcz, I. and U. Kafri (1978). Evaluation of suposed archaeoseismic damage in Israel, Journal Archaeological Science, 5, 237-253.

Korjenkov, A. M. and E. Mazor (1999). Earthquake characteristics reconstructed from archaeological damage patterns: Shivta, the Negev Desert, Israel, Israel J. Earth Sci., 48, 256-282.

Liberatore, D., G. Spera, A. Claps and A. Larotonda (2003). The Italian archaeological heritage: a classification of types from the point of view of protection against earthquakes, in Proceedings of the First International Congress on Construction History, Madrid, 1295-1305.

Lawrence, A.W. (1957). Ancient Greek Architecture, Penguin Books, Baltimore, $327 \mathrm{pp}$.

Mallet, R. (1862). Great Neapolitanian earthquake of 1857, in The First Principles of Observational Seismology, 2, Chapman and Hall, London, 1600 pp.

Maran, J. (2010). Tiryns, in The Oxford Handbook of the Bronze Age Aegean (ca. 3000-1000 BC) E.H. Cline (edt.), Oxford University Press, Inc., 722-736.

Marco, S. (2008). Recognition of earthquake-related damage in archaeological sites: Examples from the Dead Sea fault zone, Tectonophysics, 453, 148-156.

Mazor E. and A. Korjenkov (2001). Applied archaeoseismology: Decoding earthquake parameters recorded in archaeological ruins, in The Makhteshim Country: laboratory of nature B. Krasnov and E. Mazor (eds.), Pensoft, Sofia, Moscow, 123-153.

Mistler, M., C. Butenweg and K. Meskouris (2006). Modeling methods of historic masonry buildings under seismic excitation, Journal of Seismology, 10, 497-510.

Purvance, M.D., A. Anooshehpoor and J. N. Brune (2008). Freestanding block overturning fragilities: Numerical simulation and experimental validation, Earthq. Eng. Struct. Dyn., 35, 791-808.

Psycharis, I. N. (2007). A probe into the seismic history of Athens, Greece, from the current state of a classical monument, Earthq. Spectra, 23,393-415.

Scranton, R. L. (1962). Greek Architecture, Prentice-Hall International, $128 \mathrm{pp}$.

Sinopoli, A. (1995). Earthquakes and large block monumental structures, Ann. Geophis., 38, 737-751.

Torres, H.E. (2014). Builders in pre-Hispanic Peruvian Andes: analytical approaches to knowledge their seismic resistance, in 9th International Conference on Structural Analysis of Historical Constructions F. Peña and M. Chávez (eds.), Mexico City, www. 
hms.civil.uminho.pt/sahc/2014/topic08-fullpaper034.pdf, last accessed June 2016.

Wright, G.R.H. (2009). Ancient Building Technology, Volume 3: Construction, Brill, Leiden, 670 pp.

Yerli, B., J.H. ten Veen, and M. Sintubin (2011). Testing a logic tree approach for archaeoseismology to the ancient city of Pinara (SW Turkey), Quaternary International, 242, 52-64.

Yerli, B., J.H. ten Veen, M. Sintubin, V. Karabacak, C. Yalc and E. Altunel (2010). Assessment of seismically induced damage using Lidar: The ancient city of Pinara (SW Turkey) as a case study, in Ancient Earthquakes M. Sintubin, I.S. Stewart, T.M. Niemi and E. Altunel (Eds.), Geological Society of America, Boulder Co, Special Paper 471, 157-170.

Zhang, J., and N. Makris (2001). Rocking response of free-standing blocks under cycloidal pulses, J. Eng. Mechanics, 127, 473-483.

The online material can be downloaded at: http:/ / www.seismo.uni-koeln.de/esupp/AoG/H/index.htm

${ }^{*}$ Corresponding author: Klaus-G. Hinzen,

Erdbebenstation Bensberg, Universität zu Köln, Bergisch Gladbach, Germany; email: hinzen@uni-koeln.de

2017 by Istituto Nazionale di Geofisica e Vulcanologia.

All rights reserved 